\title{
Diagnostische referentieniveaus in Nederland
}

NCS platform "Stralingsbescherming in het ziekenhuis"

NEDERLANDSE COMMISSIE VOOR STRALINGSDOSIMETRIE

Rapport 21 van de Nederlandse Commissie voor Stralingsdosimetrie Juni 2012 


\section{Disclaimer regarding NCS reports}

The NCS frequently publishes reports for fellow professionals in which recommendations are given for various quality control procedures or otherwise. The members of the NCS board and the members of the concerning subcommittee do not claim any authority exceeding that of their professional expertise. Responsibility on how the NCS recommendations are implemented lies with the user, taking into account the practice in his/her institution.

NCS, Delft, The Netherlands

For more information on NCS reports, see http://www.stralingsdosimetrie.nl or http://www.radiationdosimetry.org 


\section{Preface}

The Netherlands Commission on Radiation Dosimetry (Nederlandse Commissie voor Stralingsdosimetrie, NCS) was officially established on September 3rd, 1982 with the aim of promoting the appropriate use of dosimetry of ionising radiation both for scientific research and for practical applications. The NCS is chaired by a board of scientists, installed upon the suggestion of the supporting societies, including the Netherlands Society for Radiotherapy and Oncology (Nederlandse Vereniging voor Radiotherapie en Oncologie), the Dutch Society of Nuclear Medicine (Nederlandse Vereniging voor Nucleaire Geneeskunde), the Dutch Society for Medical Physics (Nederlandse Vereniging voor Klinische Fysica), the Netherlands Radiobiological Society (Nederlandse Vereniging voor Radiobiologie), the Society of Radiological Protection of The Netherlands (Nederlandse Vereniging voor Stralingshygiëne), the Dutch Society for Medical Imaging and Radiotherapy (Nederlandse Vereniging Medische Beeldvorming en Radiotherapie), the Radiological Society of The Netherlands (Nederlandse Vereniging voor Radiologie), the Belgian Hospital Physicists Association (Belgische Vereniging voor Ziekenhuisfysici/Société Belge des Physiciens des Hôpitaux) and the Dutch society of technicians and other specialists in the field of medical physics (Nederlandse Vereniging van Klinisch Fysisch Medewerkers).

To pursue its aims, the NCS accomplishes the following tasks: participation in dosimetry standardisation and promotion of dosimetry intercomparisons, drafting of dosimetry protocols, collection and evaluation of physical data related to dosimetry. Furthermore, the commission shall maintain or establish links with national and international organizations concerned with ionising radiation and promulgate information on new developments in the field of radiation dosimetry.

Current members of the board of the NCS:

J.B. van de Kamer, Chairman T.W.M. Grimbergen, Vice-Chairman J. de Pooter, Secretary J.M.J. Hermans, Treasurer A. Van Der Plaetsen

A. Spilt

F.W. Wittkämper

D. Zweers

A.A. Lammertsma

P. Sminia

K. Franken 


\section{NCS platform "Stralingsbescherming in het ziekenhuis"}

In 1999 werd onder de auspiciën van de NCS het NCS Platform voor "Dosimetrie voor Radiologie en Nucleaire Geneeskunde" opgericht. De huidige naam van dit NCS platform luidt "Stralingsbescherming in het ziekenhuis". In dit Platform zijn vertegenwoordigers van de Nederlandse Vereniging voor Radiologie (NVvR), de Nederlandse Vereniging voor Klinische Fysica (NVKF), de Nederlandse Vereniging Medische Beeldvorming en Radiotherapie (NVMBR), de Nederlandse Vereniging voor Nucleaire Geneeskunde (NVNG) en de Nederlandse Vereniging voor Stralingshygiëne (NVS) opgenomen.

Het Platform is opgericht met als doel om in ondersteuning en advies te voorzien bij projecten op het gebied van de dosimetrie binnen de radiologie en nucleaire geneeskunde. Het Platform was betrokken bij de ontwikkeling van het Informatiesysteem voor Medische Stralingstoepassingen (project van het RIVM en het ministerie van VWS) en bij het demonstratieproject patiëntendosimetrie (project van ZONmw en het Leids Universitair Medisch Centrum). Het Platform begeleidde eerder het QC Light project ten behoeve van routinematige kwaliteitscontrole binnen de Radiologie en gaf eveneens advies aan het NCS subcommittee dat een code of practice opstelde voor persoonsdosimetrie bij gebruik van persoonlijke beschermingsmiddelen, zoals loodschorten (NCS rapport 19 ondersteund door het ministerie van SZW). Door middel van de voorliggende publicatie beoogt het NCS Platform bij te dragen aan de vaststelling van diagnostische referentieniveaus in Nederland. Het Platform kan tevens voor continuïteit zorgen bij de implementatie van diagnostische referentieniveaus in Nederland en het kan signaleren of een verdere ontwikkeling van referentieniveaus wenselijk is.

Leden van het NCS platform "Stralingsbescherming in het ziekenhuis":

Kees Visscher (voorzitter, NVRO) Paul Jonkergouw (secretaris, NVS) Bradley Pieters (NVRO) Marja Harbers (NVKFM) Jeroen Zöllner (NVMBR) Koos Geleijns (NVvR) Kirsten Schimmel (NVZA) Christiaan van Swol (NVKF) Dirk Zweers (NVMBR) Lieke Poot (NVNG) Aart van der Molen (NVvR) Roel Claessens (NVNG) Jeroen van de Kamer (NCS) 


\section{Diagnostische referentieniveaus in Nederland}

Dit NCS protocol over "Diagnostische referentieniveaus in Nederland" werd opgesteld door auteurs die een goede afspiegeling vormden van Nederlandse beroepsbeoefenaren die betrokken zijn bij de toepassing van ioniserende straling bij medisch beeldvormende technieken.

De auteurs verrichtten hun werk als werkgroep van het NCS Platform "Stralingsbescherming in het ziekenhuis" (voorheen NCS Platform "Dosimetrie voor Radiologie en Nucleaire Geneeskunde"). De werkzaamheden werden met subsidie van het Ministerie van VWS uitgevoerd. Het NCS Platform voor "Stralingsbescherming in het ziekenhuis" zal, in samenwerking met het Ministerie van VWS, het RIVM en de betrokken beroepsverenigingen, de implementatie van diagnostische referentieniveaus in Nederland actief blijven volgen en begeleiden ${ }^{1}$.

Auteurs:

Wouter J.H. Veldkamp (voorzitter)

Arjen Becht

Ramona W. Bouwman

Ad den Boer

Cecile R.L. Crompvoets-Jeukens

Tanya Geertse

Koos Geleijns

Herma Holscher

Willy A. Hummel

Aart J. van der Molen

Rutger-Jan Nievelstein

Paul Stoop

Arnold Schilham

Geert.J. Streekstra

Enno van der Velde

Dirk Zweers

Projectmanagers:

Wendy C. Krispijn

Dirk Zweers

NCS, Delft, The Netherlands

Diagnostische Referentieniveaus in Nederland

Juni 2012

\footnotetext{
${ }^{1}$ For more information on NCS Reports, see http://www.stralingsdosimetrie.nl/
} 


\section{Inhoudsopgave}

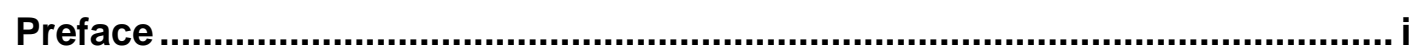

NCS Platform voor "Stralingsbescherming in het ziekenhuis" ....................... ii

Diagnostische referentieniveaus in Nederland ............................................. iii

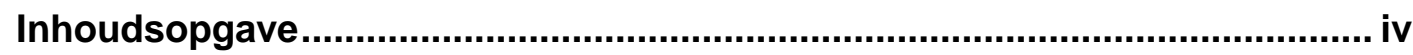

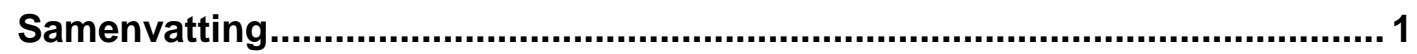

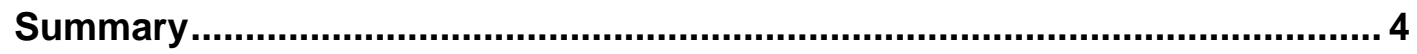

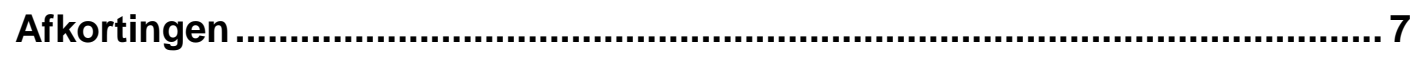

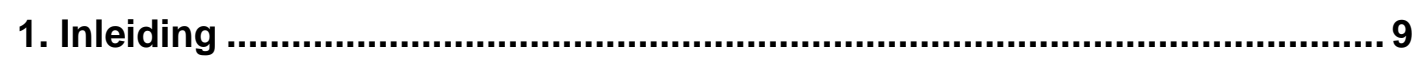

2. Diagnostische referentieniveaus: algemene overwegingen ..................... 13

2.1. Diagnostische procedures.................................................... 13

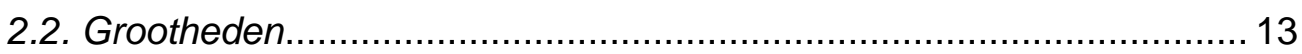

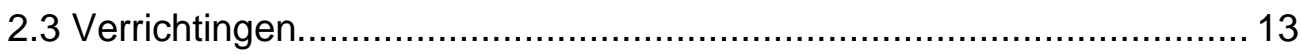

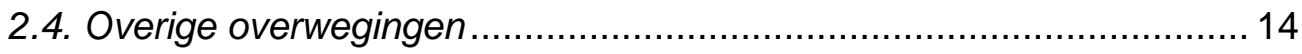

3. Implementatie van de diagnostische referentieniveaus ............................ 19

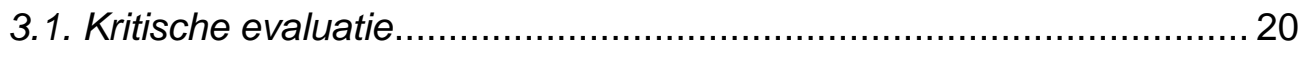

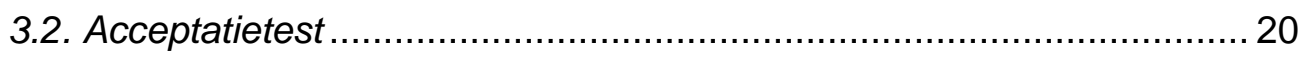

3.3. Inbedrijfstelling .................................................................... 20

3.4. Routinematige kwaliteitscontrole .............................................. 20

3.5. Toetsing aan diagnostische referentieniveaus ................................ 21

3.6. Inbedding van diagnostische referentieniveaus............................... 21

4. Diagnostische referentieniveaus en streefwaarden.................................... 23

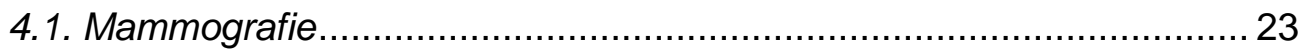

4.2. CT pulmonale angiografie en CT-abdomen ................................... 26

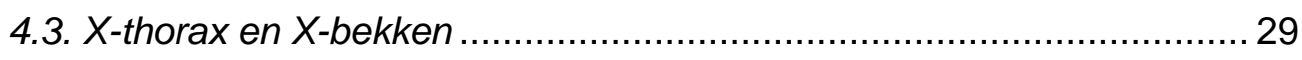

4.4 Kinderradiologie: röntgenopnamen: $X$-thorax, X-abdomen.................. 31

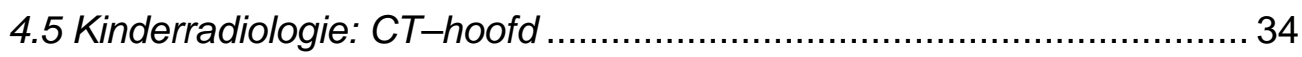

4.6 Kinderradiologie: Mictie Cysto-Urethrogram (MCUG)....................... 37

4.7 CT coronaire angiografie ............................................................. 39

4.8 Conventionele coronaire angiografie: diagnostisch .......................... 42

4.9 Overzicht van alle DRN's en streefwaarden................................... 44

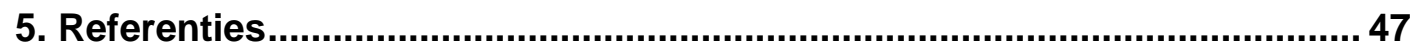




\section{Samenvatting}

In het huidig systeem van gezondheidszorg neemt beeldvormende diagnostiek met röntgenstraling een steeds belangrijker plaats in. Het aantal röntgenverrichtingen neemt gestaag toe, en er wordt meer gebruik gemaakt van geavanceerde technieken zoals computer tomografie. Hiermee is het mogelijk de kwaliteit van de zorg te verbeteren, maar tegelijkertijd neemt de stralingsbelasting van patiënten toe. Uiteraard staat bij beeldvormende diagnostiek centraal dat de beeldkwaliteit die wordt verkregen met het röntgenonderzoek goed genoeg is voor het stellen van de diagnose. Daarnaast is het van groot belang dat tevens de stralingsbescherming voor de patiënt die het röntgenonderzoek ondergaat voldoende wordt geborgd. De introductie van diagnostische referentieniveaus in Nederland kan hieraan bijdragen.

De aanleiding voor het vaststellen van Nederlandse diagnostische referentieniveaus voor Radiologie en Cardiologie is het Besluit Stralingsbescherming (BS) van de Kernenergiewet, welke de wettelijke basis voor diagnostische referentieniveaus vormt [29]. Het diagnostisch referentieniveau (DRN) is een niveau voor de blootstelling van de standaardpatiënt waaronder normaal gesproken sprake is van 'good medical practice'. Bij gangbare klinische vraagstellingen en goede diagnostische en technische prestaties zouden diagnostische referentieniveaus tijdens standaardprocedures niet moeten worden overschreden. Bij gebruik van moderne beeldvormende apparatuur en optimalisatie van het acquisitieprotocol is zelfs een veel lager dosisniveau haalbaar. Daarom wordt in dit rapport voor een aantal verrichtingen ook een streefwaarde voor de dosis vermeld. Bij een waargenomen overschrijding van een diagnostisch referentieniveau wordt verwacht dat de gebruiker extra inspanningen levert om te komen tot optimalisatie van de dosis bij de betreffende (en vergelijkbare) verrichting waarbij de beelden van voldoende diagnostische kwaliteit dienen te zijn. Een diagnostisch referentieniveau is uitdrukkelijk geen dosislimiet en is niet toepasbaar op individuele patiënten. Het is toepasbaar op de standaardpatiënt (in de praktijk af te leiden uit een groep patiënten) of op standaardfantomen.

In hoofdlijnen beschrijft dit rapport: (1) inbedding van diagnostische referentieniveaus binnen de bestaande systemen van kwaliteitsborging, (2) de dosisgrootheden van de referentieniveaus en een korte beschrijving van de methodieken voor het meten van dosiswaarden, (3) streefwaarden voor de blootstelling van patiënten die kenmerkend zijn voor geoptimaliseerde praktijken en (4) getalswaarden voor diagnostische referentieniveaus (bovengrens voor 'good medical practice'). 
Met de in dit rapport beschreven systematiek wordt beoogd dat de introductie van diagnostische referentieniveaus bijdraagt aan de optimalisatie van het diagnostisch röntgenonderzoek en dat de implementatie zo goed mogelijk aansluit bij de klinische praktijk.

De verrichtingen waarvoor diagnostische referentiewaarden zijn vastgesteld zijn mammografie, röntgenopnamen, computer tomografie en diagnostisch doorlichten. De vastgestelde referentiewaarden hebben betrekking op diagnostisch onderzoek van volwassenen en kinderen, en betreffen verrichtingen binnen de afdelingen radiologie en cardiologie. De geselecteerde onderzoeken vormen een goede afspiegeling van de huidige diagnostische praktijk. Wanneer op een afdeling wordt voldaan aan de in dit rapport gedefinieerde DRN's, dan wordt het als aannemelijk verondersteld dat de betreffende afdeling voor wat betreft de optimalisatie van röntgenverrichtingen ook in bredere zin voldoet aan zekere minimum eisen.

Tabel 1 geeft een overzicht van de vastgestelde diagnostische referentieniveaus en de streefwaarden. 
Tabel 1. Overzicht diagnostische referentieniveaus en de streefwaarden in Nederland.

\begin{tabular}{clll}
\hline Mammografie, GGD, mGy & & & \\
$3 \mathrm{~cm}$ PMMA & GGD & 1.5 & $\left.1.0^{*}\right)$ \\
$5 \mathrm{~cm}$ PMMA & GGD & 3.0 & $\left.2.4^{*}\right)$ \\
$7 \mathrm{~cm}$ PMMA & GGD & 6.5 & $\left.5.1^{*}\right)$
\end{tabular}

\begin{tabular}{|c|c|c|c|}
\hline \multicolumn{4}{|c|}{ Computer tomografie, CTDI, mGy / DLP, mGy.cm **) } \\
\hline CT abdomen & CTDI / DLP $\left.{ }^{* * *}\right)$ & $15 / 700$ & $8 / 400$ \\
\hline CTPA thorax & CTDI / DLP $\left.{ }^{* * *}\right)$ & $10 / 350$ & $6 / 200$ \\
\hline
\end{tabular}

\begin{tabular}{|c|c|c|c|}
\hline \multicolumn{4}{|c|}{ Röntgenopnamen, DOP, $\mu \mathrm{Gy} \cdot \mathrm{m}^{2}{ }^{* \star}$ ) } \\
\hline X-thorax PA & DOP & 12 & $6 *)$ \\
\hline X-bekken AP & DOP & 300 & 150 *) \\
\hline
\end{tabular}

Kinderradiologie, $\mu \mathrm{Gy} \cdot \mathrm{m}^{2}$, neonaat / 1 jaar / 5 jaar, geen grid behalve 5 jaar abdomen
$X$-thorax AP/PA
DOP
$1.5 / 2.0 / 5.0$
$\left.0.75 / 1.0 / 2.5^{*}\right)$
$X$-abdomen AP
DOP
$1.5 / 10.0 / 25.0$
$\left.0.75 / 5.0 / 12.5^{*}\right)$

Kinderradiologie, computer tomografie, CTDI, mGy / DLP, mGy.cm, neonaat / 1 jaar / 5 jaar / 10 jaar
CT hoofd
CTDI $\left.^{* * *}\right)$
20 / 25 / 35 / 50
15 / 20 / 25 / 35
CT hoofd
DLP
240 / 300 / 420 / 600
$180 / 240 / 300 / 420$

Mictie Cysto-Urethrogram, DOP, $\mu \mathrm{Gy} \cdot \mathrm{m}^{2}$, neonaat / 1 jaar / 5 jaar
MCUG
DOP
$30 / 70$ / 80
$10 / 20 / 60$

CT coronaire angiografie, CTDI, mGy / DLP, mGy.cm **)
CTCA
CTDI / DLP ${ }^{\star * *}$ )
$\left.80 / 1000^{* * *}\right)$
$\left.25 / 300^{* * * *}\right)$

\section{Diagnostische coronaire angiografie, DOP, $\mu \mathrm{Gy} \cdot \mathrm{m}^{2 * \star}$ )}

CAG

DOP

8000

3000

*) De streefwaarden hebben uitsluitend betrekking op digitale mammografie of digitale röntgenopnamen (DR), ze zijn niet van toepassing op fosforplaten (CR) of film scherm combinaties

**) Gemiddeld voor 77 kg volwassen

$\left.{ }^{* * *}\right) \mathrm{CTDI}_{\mathrm{vol}, 100}$ (spiraal) of CTDI $\mathrm{w}, 100$ (step and shoot)

${ }^{* * * *}$ ) Diagnostisch referentieniveau voor spiraal CT met een retrospectieve ECG gated reconstructie zonder modulatie van de buisstroom; streefwaarde voor prospectief ECG getriggerde step and shoot of spiral acquisitie 


\section{Summary}

Diagnostic X-ray imaging plays an increasingly important role in the current healthcare system. The number of X-ray examinations is steadily increasing, and there is increasing use of advanced techniques such as computed tomography. This enables improvement of the quality of care, but as a consequence radiation exposure to patients increases. Obtaining the required image quality for a specific diagnosis is of course the primary objective in diagnostic radiology. In addition it is also important that radiation protection for patients who undergo Xray imaging must be sufficiently secured too. The introduction of diagnostic reference levels in the Netherlands can contribute to achieve this.

The motivation for establishing Dutch diagnostic reference levels for Radiology and Cardiology, lies in the Radiation Protection Decree of the Nuclear Energy Act, which forms the legal basis for the introduction of the diagnostic reference levels. The diagnostic reference level is an upper limit for the exposure of the patient that still can be considered as 'good medical practice'. Diagnostic reference levels should not be exceeded in standard procedures associated to common clinical referrals and good diagnostic and technical performance. A much lower dose level compared to the diagnostic reference level is achievable when using modern imaging equipment and optimized acquisition protocols. Therefore, in this report, an achievable dose level has been defined for certain practices in addition to the diagnostic reference level. In case it is observed that a diagnostic reference level is exceeded, than it is expected that the user takes additional measures to achieve appropriate optimization of the concerning (and comparable) practices. A diagnostic reference level is explicitly not a dose limit and is not applicable to individual patients. It is applicable to the standard patient (in practice, to be deduced from a group of patients) or to standard phantoms.

Broadly this report describes: (1) incorporation of diagnostic reference levels within the existing systems of quality assurance, (2) the dose quantities of the reference levels and a brief description of the methods for measuring dose values, (3) achievable dose levels for the exposure of patients that are associated to optimized practices, and (4) numerical values for diagnostic reference levels as an upper limit for 'good medical practice'.

The introduction of diagnostic reference levels as described in this report is intended to contribute to the optimization of diagnostic X-ray imaging, taking into account that the 
implementation of the diagnostic reference levels matches as good as possible with clinical practices.

The examinations for which diagnostic reference levels have been established are mammography, radiography, computed tomography and diagnostic fluoroscopy. The established reference values relate to diagnostic imaging of adults and children, and cover practices within the radiology and cardiology departments. The selected studies are a good reflection of relevant operations in the current clinical diagnostic practice. When a department meets the diagnostic reference levels as defined in this report, than it is a plausible assumption that also other practices at that department (for which no diagnostic reference level has been formulated) are optimized and that they broadly meet certain minimum requirements.

Table 1 provides an overview of diagnostic reference levels and achievable dose levels in The Netherlands. 
Table 1. Overview diagnostic reference levels and achievable dose levels in The Netherlands Diagnostic reference level Achievable dose level

\begin{tabular}{cccc}
\hline \multicolumn{2}{l}{ Mammography, MGD, mGy } & & \\
$3 \mathrm{~cm}$ PMMA & MGD & 1.5 & $\left.1.0^{*}\right)$ \\
$5 \mathrm{~cm}$ PMMA & MGD & 3.0 & $\left.2.4^{*}\right)$ \\
$7 \mathrm{~cm}$ PMMA & MGD & 6.5 & $\left.5.1^{*}\right)$ \\
\hline
\end{tabular}

Computed tomography, CTDI, mGy / DLP, mGy.cm **)
CT abdomen
CTDI / DLP ${ }^{* * *}$ )
$15 / 700$
$8 / 400$
CTPA chest
CTDI / DLP ${ }^{* * *}$ )
$10 / 350$
$6 / 200$

\begin{tabular}{|c|c|c|c|}
\hline \multicolumn{4}{|c|}{ Radiography, DAP, $\mu$ Gy· $m^{2}{ }^{\star \star}$ ) } \\
\hline PA chest & DAP & 12 & $6 *$ \\
\hline AP pelvis & DAP & 300 & $150 *)$ \\
\hline
\end{tabular}

Pead. Radiography, $\boldsymbol{\mu G y} \cdot \mathrm{m}^{2}$, neonate / 1 year / $\mathbf{5}$ year, no grid except abdomen $\mathbf{5}$ year
AP/PA chest
DAP
$1.5 / 2.0 / 5.0$
$\left.0.75 / 1.0 / 2.5^{*}\right)$
AP abdomen
DAP
$1.5 / 10.0 / 25.0$
$0.75 / 5.0 / 12.5$ *)

Peadiatric computed tomography, CTDI, mGy / DLP, mGy.cm, neonate / 1 year / 5 year / 10 year
CT head
CTDI ${ }^{* * *}$ )
20 / 25 / 35 / 50
$15 / 20 / 25 / 35$
CT head
DLP
240 / 300 / 420 / 600
180 / $240 / 300 / 420$

\section{Micturating Cystourethrogram, DAP, $\mu \mathrm{Gy} \cdot \mathrm{m}^{2}$, neonate / 1 year / 5 year}
MCUG
DAP
$30 / 70 / 80$
$10 / 20 / 60$

CT coronary angiography, CTDI, mGy / DLP, mGy.cm **)
CTCA
CTDI / DLP ${ }^{* * *}$ )
$\left.80 / 1000^{* * *}\right)$
$\left.25 / 300^{* * * *}\right)$

\section{Diagnostic coronary angiography, DAP, $\mu \mathrm{Gy} \cdot \mathrm{m}^{2 * \star}$ ) \\ CAG \\ DAP \\ 8000 \\ 3000}

\footnotetext{
$\left.{ }^{\star}\right)$ Achievable levels are only applicable to digital mammography or radiography (DR), and not applicable to phosphor plates (CR) or film screen.

$\left.{ }^{* *}\right)$ Average sized $77 \mathrm{~kg}$ adult

$\left.{ }^{* * *}\right)$ CTDI $_{\mathrm{vol}, 100}$ (spiral) of CTDI $\mathrm{w}, 100_{\text {(step and shoot) }}$

${ }^{* * * *}$ ) Diagnostic reference level for a spiral CT acquisition and retrospective ECG gated reconstruction;

achievable level for a step and shoot or helical prospective ECG triggered acquisition
} 


\section{Afkortingen}

\begin{tabular}{|c|c|}
\hline AAPM & American Association of Physicists in Medicine \\
\hline AEC & automatic exposure control (automatische belichtingsregeling) \\
\hline AP & anterior posterior (voorachterwaartse stralingsrichting) \\
\hline BMI & body mass index \\
\hline CAG & Coronaire AngioGrafie \\
\hline CBS & Centraal Bureau voor de Statistiek \\
\hline $\mathrm{CR}$ & computed radiography (röntgenopnamen met behulp van fosfor platen) \\
\hline CT & computer tomografie \\
\hline CT-abdomen & CT onderzoek van de buik en het bekken \\
\hline CT-thorax & CT onderzoek (angiografie) van de thorax \\
\hline CTCA & CT coronaire angiografie \\
\hline CTPA & CT pulmonale angiografie \\
\hline CTDI & computer tomografie-dosisindex \\
\hline DAP & Dose Area Product \\
\hline DIN & Deutsches Institut für Normung \\
\hline DLP & dosis-lengteproduct \\
\hline DOP & dosis-oppervlakteproduct \\
\hline DR & digital radiography (direct digitale röntgenopnamen) \\
\hline DRN & diagnostisch referentieniveau \\
\hline EU & Europese Unie \\
\hline GGD & gemiddelde glandulaire dosis \\
\hline HVL & half value layer (halfwaarde dikte) \\
\hline IEC & International Electrotechnical Commission \\
\hline IPEM & Institute of Physics and Engineering in Medicine \\
\hline LUMC & Leids Universitair Medisch Centrum \\
\hline MCUG & Mictie Cysto-Urethrogram \\
\hline MGD & mean glandular dose (gemiddelde glandulaire dosis) \\
\hline Ministerie van VWS & Ministerie van Volksgezondheid, Welzijn en Sport \\
\hline NCS & Nederlandse Commissie voor Stralingsdosimetrie \\
\hline NVVC & Nederlandse Vereniging voor Cardiologie \\
\hline NVKF & Nederlandse Vereniging voor Klinische Fysica \\
\hline NVMBR & Nederlandse Vereniging Medische Beeldvorming en Radiotherapie \\
\hline NVNG & Nederlandse Vereniging voor Nucleaire Geneeskunde \\
\hline NVS & Nederlandse Vereniging voor Stralingshygiëne \\
\hline
\end{tabular}




$\begin{array}{ll}\text { NVvR } & \text { Nederlandse Vereniging voor Radiologie } \\ \text { PA } & \text { posterior anterior (achtervoorwaartse stralingsrichting) } \\ \text { PMMA } & \text { polymethylmetacrylaat (perspex) } \\ \text { QA } & \text { quality assurance (kwaliteitsborging) } \\ \text { QC } & \text { quality control (kwaliteitscontrole) } \\ \text { RIVM } & \text { Rijksinstituut voor Volksgezondheid en Milieu } \\ \text { X-abdomen } & \text { röntgenfoto van de buik } \\ \text { X-thorax } & \text { röntgenfoto van de thorax }\end{array}$




\section{Inleiding}

In het huidig systeem van gezondheidszorg neemt beeldvormende diagnostiek met röntgenstraling een steeds belangrijker plaats in. Het aantal röntgenverrichtingen neemt gestaag toe, en er wordt meer gebruik gemaakt van geavanceerde technieken zoals computer tomografie. Hiermee is het mogelijk de kwaliteit van de zorg te verbeteren, maar tegelijkertijd neemt de stralingsbelasting van patiënten toe. Uiteraard staat bij beeldvormende diagnostiek centraal dat de beeldkwaliteit die wordt verkregen met het röntgenonderzoek goed genoeg is voor het stellen van de diagnose. Daarnaast is het ook van belang dat de stralingsbescherming voor de patiënt die het röntgenonderzoek ondergaat voldoende wordt geborgd. De introductie van diagnostische referentieniveaus kan hieraan bijdragen.

De aanleiding voor het vaststellen van diagnostische referentieniveaus is een artikel in het Besluit stralingsbescherming van de Kernenergiewet [29]. Dit artikel luidt: "Onze Minister bevordert de vaststelling en het gebruik van diagnostische referentieniveaus voor radiodiagnostische verrichtingen als bedoeld in artikel 53 , lid1, alsmede het opstellen van protocollen ter zake".

Het begrip diagnostisch referentieniveau vindt zijn oorsprong begin jaren negentig in het Verenigd Koninkrijk. Met behulp van referentieniveaus probeerde men de ongewenst grote spreiding in het waargenomen dosisniveau voor één en dezelfde diagnostische verrichting binnen verschillende ziekenhuizen beter te beheersen [47]. Het diagnostisch referentieniveau (DRN) werd gedefinieerd als de dosiswaarde die bij een routine onderzoek van een patiënt met een normaal postuur niet zou moeten worden overschreden. Dit normale postuur kan betrekking hebben zowel op volwassen patiënten, als op neonaten en kinderen. Praktisch zijn de eerste DRN's afgeleid uit de spreiding van dosiswaarden die werden waargenomen bij grootschalige veldonderzoeken. In het Verenigd Koningkrijk werd uit de dosisverdeling een 75-percentiel waarde afgeleid en als DRN voorgesteld ${ }^{2}$. Van afdelingen waar dosiswaarden het DRN overstegen, werd verwacht dat onderzocht zou worden of de röntgenapparatuur minder stralingsbelastend kon worden ingezet, zonder daarbij de benodigde kwaliteit van het diagnostisch onderzoek geweld aan te doen. Deze benadering heeft ertoe bijgedragen dat de stralingsbelasting bij radiologisch onderzoek in het Verenigd

\footnotetext{
${ }^{2}$ Voor de 75 -percentiel waarde geldt dat $75 \%$ van de in de veldstudie waargenomen dosiswaarden lager waren, en dat $25 \%$ van de waarden hoger of eraan gelijk waren. Met andere woorden, in driekwart van de ziekenhuizen liggen de blootstellingen onder de 75-percentiel waarde.
} 
Koninkrijk is gedaald na de introductie van diagnostische referentieniveaus in de jaren negentig [47]. Het concept van de diagnostische referentieniveaus werd in brede kring als nuttig ervaren en heeft zijn weg gevonden naar de Europese regelgeving [11] en van daaruit naar het hierboven al vermelde Besluit stralingsbescherming van de Nederlandse Kernenergiewet [29].

DRN's krijgen bij voorkeur een vaste plaats binnen het kwaliteitsborgingsysteem. De waarde van de DRN's ligt in het helpen opsporen van röntgentechnieken en -toestellen die niet aan gestelde kwaliteitseisen voldoen. Bij een waargenomen overschrijding van een diagnostisch referentieniveau wordt verwacht dat de gebruiker extra inspanningen levert om te komen tot optimalisatie van de betreffende (en vergelijkbare) verrichtingen. Dit rapport beperkt zich tot een zorgvuldige selectie van diagnostische verrichtingen die een goede afspiegeling vormen van relevante verrichtingen binnen de huidige klinische praktijk. De representatieve selectie van DRN's omvat zowel mammografie, röntgenopnamen, computer tomografie en diagnostische doorlichting en heeft betrekking op onderzoek van zowel volwassenen als neonaten en kinderen. Er wordt verwacht dat de mate waarin deze verrichtingen geoptimaliseerd zijn ook een indicatie geeft voor de mate van optimalisatie van andere toepassingen van röntgenstraling. Een DRN is uitdrukkelijk geen dosislimiet en is niet toepasbaar op individuele patiënten. Het is zelfs denkbaar dat een afdeling besluit om een overschrijding van een diagnostisch referentieniveau (tijdelijk) te accepteren, bijvoorbeeld wanneer met een verouderd toestel een periode moet worden overbrugd totdat een nieuw toestel in gebruik zal worden genomen.

Diagnostische referentieniveaus (DRN's) zijn in Nederland vastgesteld voor vijf gangbare diagnostische verrichtingen bij volwassenen: X-thorax (PA staand), X-bekken (AP liggend), CT pulmonale angiografie (CTPA), CT-abdomen en mammografie. In aanvulling hierop zijn DRN's vastgesteld voor kinderradiologie (X-thorax, X-abdomen, CT-hoofd en mictie cystourethrografie), en voor diagnostische coronaire angiografie door middel hartkatheterisatie en voor minimaal invasieve CT coronaire angiografie (CTCA) bij volwassenen. 
Door bijzondere inspanningen van de gebruiker op het gebied van de techniek (moderne apparatuur) en het acquisitieprotocol moet een substantieel lager dosisniveau dan het DRN haalbaar kunnen zijn. Om de optimalisatie van verrichtingen te stimuleren is derhalve voor een aantal verrichtingen een tweede dosisniveau geïntroduceerd. Naast het DRN wordt dan een streefwaarde vermeld die representatief is voor geoptimaliseerde klinische praktijken waarbij gebruik wordt gemaakt van moderne apparatuur.

Dit rapport voldoet aan de volgende vooraf opgestelde hoofddoelstellingen:

1. De mogelijkheid bieden tot inbedding van diagnostische referentieniveaus binnen de bestaande systemen van kwaliteitsborging. In dit kader omvat kwaliteitsborging alle geplande en systematische verrichtingen die noodzakelijk zijn om voldoende zekerheid te geven dat een structuur, systeem, onderdeel of procedure naar behoren en in overeenstemming met algemeen aanvaarde normen functioneert.

2. Het selecteren van dosimetrische meetmethoden en grootheden die optimaal aansluiten bij de klinische praktijk.

3. Het waar mogelijk vermelden van streefwaarden voor de blootstelling van patiënten die kenmerkend zijn voor geoptimaliseerde praktijken.

4. Het vaststellen van getalswaarden voor de diagnostische referentieniveaus waarmee praktijken die niet aan de huidige kwaliteitseisen voldoen effectief kunnen worden gesignaleerd.

Startpunt voor het opstellen van dit rapport waren relevante publicaties op het gebied van DRN's $[1 ; 4 ; 11 ; 13 ; 25 ; 27 ; 38 ; 40 ; 46 ; 47]$, en in het bijzonder het verslag van het Nederlandse demonstratieproject patiëntendosimetrie [42]. Aan de basis lagen tevens de aanbevelingen van de Gezondheidsraad met betrekking tot DRN's in haar rapport 'Risico's van blootstelling aan ioniserende straling' [16].

Dit rapport werd samengesteld door een werkgroep 'Diagnostische Referentieniveaus in Nederland' onder supervisie van het NCS Platform "Stralingsbescherming in het ziekenhuis". De activiteiten van het NCS Platform en de werkgroep werden mede gestart op initiatief van het ministerie van VWS. Het NCS Platform biedt een structuur waarbinnen de continuïteit van de implementatie van diagnostische referentieniveaus in Nederland kan worden gewaarborgd. Hierbij wordt aangeraden de nadruk te leggen op het up-to-date houden van de DRN's en niet op uitbreiding van het aantal verrichtingen. Dat laatste zou de praktisch uitvoerbaarheid van de DRN-systematiek negatief kunnen beinvloeden. 
Ten slotte, dit rapport is het eindresultaat van het zogenoemde fase 3 project uitgevoerd door de bovengenoemde werkgroep. De werkgroep kwam in de eerdere projecten (fase 1 en 2) al tot twee publicaties (zie www.referentieniveau.nl). Deze zijn nu verwerkt tot één rapport waarin nieuwe inzichten werden opgenomen. De belangrijkste wijzigingen ten opzichte van de eerdere twee publikaties zijn:

- In de eerste publicatie werd gekozen voor het buikoverzicht AP in rugligging. Naar aanleiding van een door de werkgroep uitgevoerde veldstudie, is echter de conclusie getrokken dat het buikoverzicht relatief weinig wordt gemaakt. Daarom is besloten om het bekkenoverzicht AP liggend te kiezen. Deze verrichting wordt aanzienlijk vaker gemaakt waardoor in een relatief korte tijd een relevant aantal dosiswaarden kan worden verzameld.

- In de eerste twee publicaties werd het begrip 'haalbare waarde' gehanteerd als een waarde die realiseerbaar is bij gebruik van moderne diagnostische apparatuur. Het begrip leidde tot verwarring omdat de gerelateerde waarde niet altijd haalbaar is, bijvoorbeeld voor minder moderne apparatuur. Als alternatief is in dit rapport de term 'streefwaarde' gehanteerd.

- Bij mammografie zijn er in de eerste publicatie twee DRN's vastgesteld. Dit wijkt af van de situatie bij andere modaliteiten. Bij andere modaliteiten is er namelijk één DRN en een streefwaarde vastgesteld. Het bestaan van twee DRN's bij mammografie (respectievelijk voor DR en CR) in de eerste DRN publicatie bleek na evaluatie en feedback uit het veld ongewenst. Voor DR mammografie systemen is nu een streefniveau gedefinieerd, één DRN is van toepassing op zowel CR als DR mammografiesystemen. 


\section{Diagnostische referentieniveaus: algemene overwegingen}

\subsection{Diagnostische procedures}

Diagnostische referentieniveaus (DRN's) zijn vastgesteld voor vijf gangbare diagnostische verrichtingen bij volwassenen: X-thorax, X-bekken, CT pulmonale angiografie, CT-abdomen en mammografie. Het criterium bij deze keuze was de substantiële bijdrage die deze verrichtingen leveren aan de collectieve dosis in Nederland, ofwel vanwege het grote aantal verrichtingen ofwel vanwege de relatief hoge dosis per verrichting. Daarnaast werd beoogd verrichtingen te selecteren die representatief zijn voor het spectrum aan radiologische verrichtingen zoals die binnen de klinische praktijk van afdelingen radiologie worden toegepast. In aanvulling op het bovenstaande zijn ook DRN's vastgesteld voor bijzondere verrichtingen, namelijk kinderradiologie (X-thorax, X-abdomen, CT-hoofd en mictie cystourethrografie $(\mathrm{MCU})$ ), diagnostische coronaire angiografie door middel van hartkatheterisatie, en van CT coronaire angiografie. De keuze voor verrichtingen binnen de kinderradiologie is vanwege de hogere gevoeligheid van kinderen voor straling. Bij coronaire angiografie, middels hartcatheterisatie of CT, golden als criteria de substantiële bijdrage die deze verrichtingen leveren aan de collectieve dosis in Nederland vanwege de relatief hoge dosis per verrichting. Toetsing aan het diagnostisch referentieniveau voor de bijzondere verrichtingen is met name relevant voor afdelingen waar deze verrichtingen regelmatig worden uitgevoerd.

\subsection{Grootheden}

Om de praktische toepassing van de diagnostische referentieniveaus te vereenvoudigen is waar mogelijk gekozen voor dosimetrische grootheden die worden weergegeven op het bedieningspaneel van het betreffende toestel. Dit was mogelijk voor alle verrichtingen met uitzondering van mammografie, het is namelijk nog niet gangbaar dat een dosisindicatie wordt getoond op het bedieningspaneel van een mammograaf.

De volgende grootheden worden gebruikt voor de diagnostische referentieniveaus [20;26]

- $\quad$ Het dosis-oppervlakte product (DOP, $\mu \mathrm{Gy} . \mathrm{m}^{2}$ ) voor röntgenopnamen en doorlichten;

- De computer tomografie-dosisindex (CTDI, mGy), en het dosis-lengteproduct (DLP, mGy.cm) voor computer tomografie; en

- $\quad$ De gemiddelde glandulaire dosis (GGD, mGy) voor mammografie.

\subsection{Verrichtingen}


Diagnostische referentiewaarden zijn vastgesteld voor vijf gangbare röntgenonderzoeken bij volwassen patiënten die op vrijwel elke afdeling radiologie regelmatig worden uitgevoerd. In aanvulling zijn diagnostische referentiewaarden vastgesteld voor kinderradiologie en coronaire angiografie.

Algemene radiologie (volwassenen)

- Mammografie (craniocaudale projectie)

- CT pulmonale angiografie (longembolie) en CT-abdomen (acute buik)

- Röntgenopnamen: X-thorax (infiltraten; PA staand) en X-bekken (artrose; AP liggend)

Kinderradiologie

- Röntgenopnamen (X-thorax, X-abdomen), leeftijd 0 (neonaat), 1 en 5 jaar

- CT-hoofd (trauma), leeftijd 0 (neonaat), 1, 5 en 10 jaar

- Mictie Cysto-Urethrogram (MCUG), leeftijd 0 (neonaat), 1 en 5 jaar

Coronaire angiografie; diagnostisch (volwassenen)

- CT coronaire angiografie (CTCA)

- Conventionele coronaire angiografie (CAG)

\subsection{Overige overwegingen}

Toetsing aan diagnostische referentieniveaus kan in het algemeen worden bereikt door middel van een analyse van de waargenomen blootstellingen bij klinisch onderzoek van patiënten, alleen bij mammografie worden dosismetingen uitgevoerd met behulp van een fantoom. Toetsing kan met nadruk nooit betrekking hebben op analyse van de dosis bij een individuele patient. De diagnostische referentieniveaus bij mammografie hebben betrekking op dosismetingen met homogene PMMA fantomen van verschillende dikte. In veel röntgentoestellen is een dosismeter geïntegreerd, het Besluit stralinsgbescherming (Art. 68 sub a) schrijft voor dat, indien nieuwe apparatuur in gebruik wordt genomen, deze een voorziening heeft die de stralingsbelasting voor de betreffende radiologische verrichting aangeeft.

Voor röntgenopnamen en doorlichten heeft het de voorkeur om uit te gaan van een analyse van de blootstellingen binnen een cohort patiënten. Metingen met fantomen zijn hierbij niet praktisch omdat er geen geschikte standaardfantomen op brede schaal beschikbaar zijn. De dosis is eenvoudig te bepalen wanneer het betreffende röntgentoestel (het thoraxstatief, de wand- of tafelbucky of het doorlichtstatief) beschikt over een voorziening die de actuele dosis 
tijdens het klinisch onderzoek meet en registreert. Hiertoe zijn alle moderne toestellen voor röntgenopnamen of doorlichten uitgerust met een dosis-oppervlakte product meter. Bij oudere toestellen ontbreekt soms de dosis-oppervlakte product meter, in dat geval is het vaak wel mogelijk tijdelijk een externe dosis-oppervlakte product meter aan te sluiten. Eventueel kan het dosis-oppervlakte product worden afgeleid uit het product van de intree dosis (vrij-in-lucht, zonder terugverstrooide straling) en het oppervlak van het intree veld.

Ook voor computer tomografie heeft het de voorkeur om uit te gaan van een analyse van de blootstellingen binnen een cohort patiënten. De dosis is eenvoudig te bepalen bij CT wanneer de betreffende scanner beschikt over een voorziening die de stralingsbelasting voor het betreffende CT onderzoek vaststelt en opslaat. Hiertoe zijn tegenwoordig alle CT scanners uitgerust met een indicatie van de CTDI en het DLP.

Uit metingen bij een representatieve groep patiënten kan het dosis-oppervlakteproduct, de CTDI of het DLP worden afgeleid dat representatief is voor het onderzoek van een gemiddelde patiënt. Bij volwassenen wordt de gemiddelde patiënt gekarakteriseerd door een gewicht van $77 \mathrm{~kg}\left({ }^{3}\right)$, bij kinderen zijn verschillende leeftijdscategorieën gedefinieerd (leeftijd 0 (neonaat), 1, 5, en bij CT ook 10 jaar).

De toestelinstellingen die gebruikt worden voor kinderradiologie zijn vanzelfsprekend sterk afhankelijk van de grootte van het kind en daarmee dus ook van de leeftijd. Voor de toepassing van de protocollen is het praktisch om van leeftijden uit te gaan. Als aanvullende informatie wordt bij de diagnostische referentiewaarden ook het gemiddelde gewicht vermeld per leeftijdscategorie om toetsingsmogelijkheden te vergroten [5].

Bij toetsing aan een DRN wordt aanbevolen om bij tenminste 20 volwassen patiënten de dosiswaarde te registreren evenals het gewicht van de patiënt ${ }^{4}$. Met de verkregen gegevens kan door middel van interpolatie de dosiswaarde worden afgeleid die van toepassing is op de

\footnotetext{
${ }^{3}$ Besloten is niet de definitie van een standaard patiënt over te nemen van het document 'Radiation Protection 109' van de EU [11], waarin een standaard patiënt wordt gedefinieerd als $70 \mathrm{~kg}$ zwaar en met een doorsnede van $27 \mathrm{~cm}$, maar om een standaardpatiënt te definiëren die de hedendaagse gemiddelde patiënt beter benadert. In 2010 rapporteert het CBS voor mannen en vrouwen (> 20 jaar, voor het jaar 2010) een gemiddeld gewicht van $77 \mathrm{~kg}$ (gemiddelde lengte is $174 \mathrm{~cm}$ ).

${ }^{4}$ Een aantal alternatieve karakteristieken voor het definiëren van de standaard patiënt werden overwogen: naast gewicht de body mass index (BMI) en de anteroposteriore (AP) diameter. Echter gezien de eenvoud van bepaling, algemene toepasbaarheid (brede toepasbaarheid m.b.t. andere verrichtingen) en redelijk goede correlatie met röntgenverzwakking werd gekozen voor gewicht. De redelijk goede correlatie van gewicht met DOP wordt bevestigd in de literatuur met betrekking tot cardiologische procedures [30;36].
} 
standaard volwassen patiënt. Vervolgens kan deze waarde worden getoetst aan de referentiewaarde. Uit de verkregen DOP waarden bij conventionele coronaire angiografie wordt echter aanbevolen de mediaan te bepalen. Vervolgens kan deze waarde worden getoetst aan de referentiewaarde. De procedure wijkt hier af van andere verrichtingen bij volwassenen omdat bij deze specifieke verrichting de DOP-waarde matig tot slecht gecorreleerd is met het gewicht.Bij kinderen wordt aanbevolen om voor de vermelde leeftijdscategorieën 20 dosiswaarden te registreren, waarna bijvoorbeeld de mediaan van deze waarden kan worden getoetst aan de referentiewaarde. Deze methodieken zijn gebaseerd op eerder toegepaste methoden in het Verenigd Koninkrijk [24].

Soms zal het moeilijk zijn informatie voor een groep van 20 patiënten per leeftijdscategorie te 'verzamelen'. Voor die gevallen wordt geadviseerd de toetsing uit te voeren met kleinere aantallen met in achtneming van de beperkingen (onzekerheden) die dit met zich meebrengt.

Veelal beschikt het röntgentoestel dus over een voorziening die de actuele dosis tijdens klinisch onderzoek meet en registreert (DOP, CTDI, DLP). Deze dosiswaarden kunnen worden gebruikt ten behoeve van toetsing aan diagnostische referentiewaarden onder de voorwaarde dat gecontroleerd is dat de dosiswaarden voldoende goed overeenkomen met de werkelijke doses. Voor criteria over de vereiste nauwkeurigheid wordt verwezen naar publicaties van IEC, DIN, IPEM en AAPM. Wenselijk is dat geconstateerde afwijkingen kleiner zijn dan 10\%, bij grotere afwijkingen moet hiervoor worden gecorrigeerd.

De nauwkeurigheid van de indicatie van het dosis-oppervlakte product kan bijvoorbeeld worden gecontroleerd door met een gekalibreerde dosismeter de dosis vrij in lucht te meten in combinatie met een meting van de corresponderende veldgrootte. Voor CT zijn de diagnostische referentieniveaus afgeleid van dosismetingen met een CT dosis fantoom en een speciale $100 \mathrm{~mm}$ lange CT ionisatiekamer. De meeste afdelingen klinische fysica in Nederland, en alle leverancies van CT scanners, beschikken over deze ionisatiekamers of detectoren en CT dosis fantomen. Voor CT onderzoek van de romp wordt een cilindervormig fantoom met een lengte van $150 \mathrm{~mm}$ en een diameter van $320 \mathrm{~mm}$ toegepast; voor scans van het hoofd wordt een cilindervormig fantoom met een lengte van $150 \mathrm{~mm}$ en een diameter van $160 \mathrm{~mm}$ toegepast.

Doorgaans geven de huidige mammografen nog geen generieke, als diagnostisch referentieniveau bruikbare, dosisindicatie op de bedieningsconsole. Wel geeft de nieuwe generatie mammografen steeds vaker de GGD weer als dosisindicatie (Engels: Mean 
Glandular Dose, MGD), maar het is niet altijd duidelijk welk mathematisch model en welke acquisitie parameters gebruikt zijn voor de bepaling van de GGD. De dosisindicatie op de mammograaf kan daardoor niet zonder meer gebruikt worden bij toetsing aan DRN's. Aanbevolen wordt om de GGD af te leiden uit metingen met PMMA fantomen van verschillende dikte.

Voor het bepalen van de GGD bij mammografie zijn protocollen [35] (EUREF) en artikelen van Dance et al. [6;7;9;10] beschikbaar. Dosimetrie bij mammografie stelt bijzondere eisen aan de nauwkeurigheid (en kalibratie) van de gebruikte dosismeter, en aan de zuiverheid van het aluminium dat nodig is voor meting van de halfwaarde dikte van de röntgenbundel.

\section{Röntgensystemen}

Bij mammografie, $\mathrm{X}$-thorax en $\mathrm{X}$-abdomen kan onderscheid worden gemaakt tussen direct digitale radiografie (DR) systemen, fosforplaat-systemen (ook wel aangeduid als 'Computed Radiography' (CR) systemen) en conventionele film-schermsystemen. CR systemen vragen, vooral bij mammografie, om relatief hogere doses om tot acceptabele beeldkwaliteit te komen. Voorzover ons bekend worden film-schermsystemen in Nederland niet meer toegepast. Voor X-thorax en X-bekken bij volwassenen en mammografie geldt dat bij gebruik van een modern DR systeem verwacht wordt dat de klinische blootstellingen aanzienlijk onder het respectievelijke diagnostisch referentieniveau zullen liggen en dat de vermelde streefwaarden relatief eenvoudig haalbaar zouden moeten zijn.

De DRN's zijn vastgesteld voor een acquisitie met een constante buisstroom. Voor de moderne CT-scanners geldt dat deze veelal de buistroom aanpassen aan het postuur van de patiënt, met andere woorden, de CT scanner zal de buistroom variëren afhankelijk van de verzwakking die de röntgenstraling ondervindt in de patiënt. Dit wordt bereikt door een aanpassing van de buisstroom aan het postuur van de patiënt en door modulatie van de buisstroom. Er wordt verwacht dat toepassing van systemen die de optimalisatie van de buisstroom mogelijk maken in de praktijk, voor een patiënt met een gemiddeld postuur, zal leiden tot dosisreductie. Voor CT coronaire angiografie zijn nieuwe acquisitie technieken ontwikkeld om de CT scan te optimaliseren zoals ECG gestuurde modulatie van de buisstroom bij een spiraal scan in combinatie met een retrospectief 'gated' reconstructie, of axiale ECG 'triggered' acquisities. Met deze nieuwe technieken voor CT coronaire angiografie zijn aanzienlijke dosisreducties mogelijk.

Toekomst 
Voor de toekomst is het van belang dosiswaarden en patiëntengegevens uit RIS/PACS systemen te kunnen verkrijgen. Momenteel blijkt dit met name voor dosiswaarden niet altijd goed mogelijk te zijn. Door de werkgroep is bij wijze van proof of concept een pragmatische applicatie ontwikkeld waarmee dosimetrische informatie uit een RIS/PACS systeem kan worden opgevraagd en waarmee kon worden aangetoond dat het automatisch verzamelen van dosisgegevens in relatie to de DRN systematiek realiseerbaar is. Bij grote cohorten kan de mediaan waarde worden bepaald en vervolgens worden getoets aan het DRN. Voor de toekomst lijkt het van belang dat fabrikanten van modaliteiten gaan voldoen aan het Integrating the Healthcare Enterprise (IHE - www.ihe.net) REM profiel. Dit Radiation Exposure Monitoring (REM) Profiel beschrijft een gestandaardiseerde manier waarop modaliteiten, PACS-en en werkstations dosisinformatie met elkaar delen en toegankelijk kunnen maken voor verdere analyse. 


\section{Implementatie van de diagnostische referentieniveaus}

De beheerder en gebruikers van diagnostische röntgentoestellen dragen gezamenlijk verantwoordelijkheid voor de periodieke toetsing aan de DRN's. De DRN's krijgen bij voorkeur een vaste plaats binnen het kwaliteitsborgingsysteem op radiologieafdelingen. Optimale inpassing in het kwaliteitsborgingsystemen zal afhangen van lokale omstandigheden.

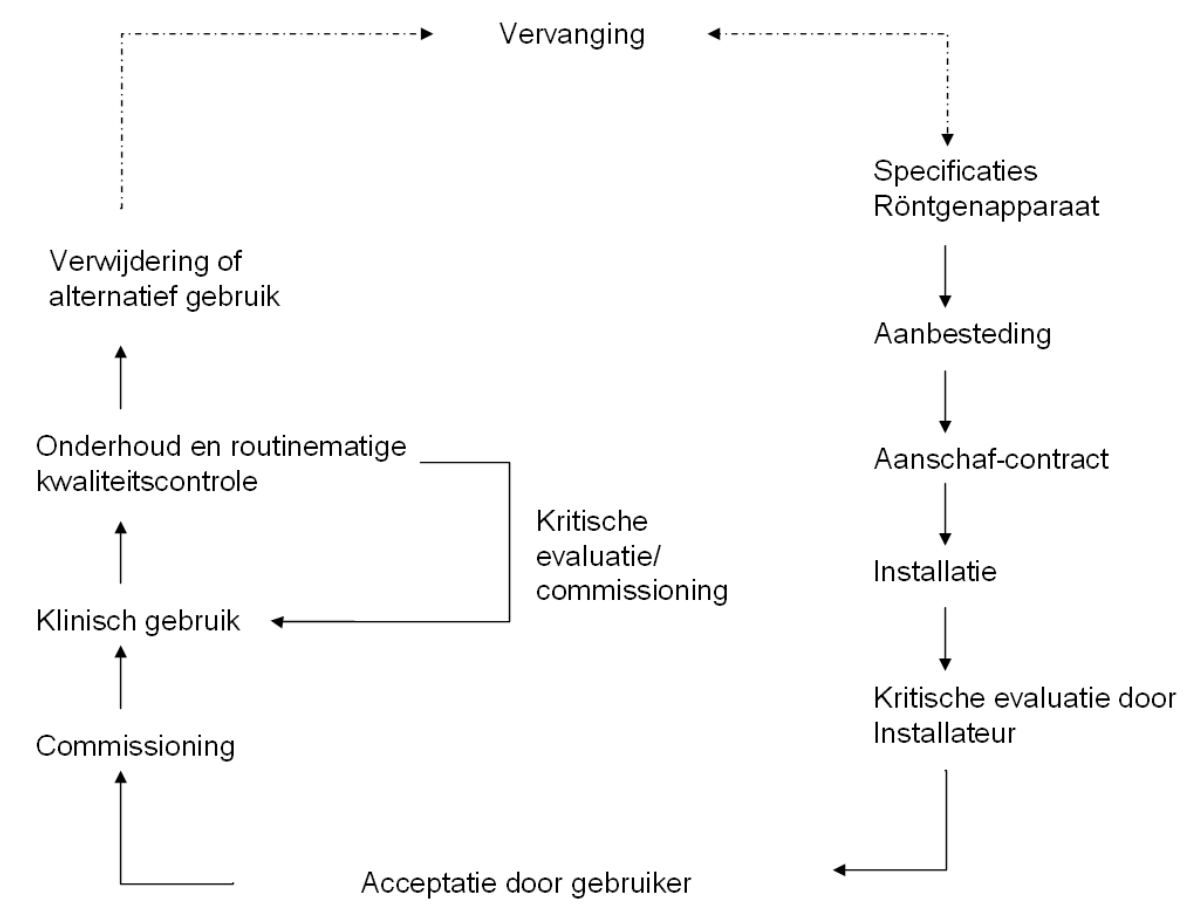

Figuur 1. De levenscyclus van een diagnostisch röntgentoestel.

Bovenstaande figuur geeft de levenscyclus weer van een diagnostisch röntgentoestel. Van nieuw aan te schaffen röntgentoestellen dient te worden gecontroleerd of de specificaties voldoende zijn om de benodigde beeldkwaliteit te bereiken bij een blootstelling voor de patiënt die beneden het DRN blijft. Er kunnen vervolgens 4 fases binnen de levenscyclus worden aangewezen waar metingen en controles in algemene zin plaatsvinden, te weten [3;23]:

1. Oplevering en kritische evaluatie door installateur

2. Acceptatietest en kritische evaluatie door gebruiker

3. Inbedrijfstelling (commissioning) en vrijgave voor klinisch gebruik

4. Routinematige kwaliteitscontrole 


\subsection{Kritische evaluatie}

Bij de kritische evaluatie wordt getest of bij een nieuw geïnstalleerd toestel, of na ingrijpend onderhoud van het toestel, de veiligheidsmechanismen die in het systeem zijn ingebouwd naar behoren werken. Dit geeft een eerste indicatie of personeel, bezoekers en patiënten voldoende beschermd en veilig zijn. Hierbij kunnen ook dosimetrische aspecten een rol spelen, zoals controle op lekstraling en controle op de beschikbaarheid van de indicatie van de patiëntdosis.

\subsection{Acceptatietest}

Bij de acceptatietest zal door de aankoper (of onder toezicht van de aankoper) worden gecontroleerd of het toestel voldoet aan alle specificaties. In deze fase zal de gebruiker zich er bijvoorbeeld van willen overtuigen dat het DOP (wandbucky, thoraxsysteem, tafelbucky, doorlichtstatief), de CTDI en het DLP (CT-scanner) en de GGD (mammograaf, indien van toepassing) voldoende nauwkeurig worden weergegeven

\subsection{Inbedrijfstelling}

De inbedrijfstelling (Engels 'commissioning') omvat een serie testen die door de aankoper worden uitgevoerd om zich ervan te verzekeren dat het toestel kan worden vrijgegeven voor klinisch gebruik. Bovendien worden hier kwaliteitsmetingen verricht waarin basis- (Engels: baseline) niveaus worden verzameld. Deze niveaus zullen als uitgangsniveaus dienen bij de latere routinematige kwaliteitscontrole. Al bij de inbedrijfstelling kan vaak worden vastgesteld of de voorgenomen protocollen voor het uitvoeren van mammografie en CT voldoen aan de diagnostische referentieniveaus. Bij de mammograaf kan de GGD voorafgaand aan de inbedrijfstelling worden gemeten, en bij CT is vaak al bekend welke CTDI en welk DLP gepaard gaan met de geïnstalleerde CT acquisitieprotocollen. In de fase van inbedrijfstelling kan de aankoper ook controleren of het klinisch toe te passen protocol voor opnamen en doorlichten voldoende geoptimaliseerd is bijvoorbeeld met betrekking tot de dosis of het dosistempo op de detector, de buislading (mAs) en de buisspanning en filtratie.

\subsection{Routinematige kwaliteitscontrole}

Routinematige kwaliteitscontrole dient om significante veranderingen in beeldkwaliteit en/of dosiswaarden waar te nemen. Waargenomen overschrijding van de toleranties op het gebied van beeldkwaliteit en/of dosiswaarden kunnen leiden tot correctieve acties, maar kunnen ook leiden tot buiten bedrijf stelling van het toestel. Een waargenomen overschrijding van een DRN betekent dat extra inspanningen nodig zijn voor optimalisatie van de betreffende verrichting, maar zal in het algemeen niet hoeven te leiden tot buitenbedrijf stelling. 


\subsection{Toetsing aan diagnostische referentieniveaus}

De eerste toetsing aan de DRN's zal vaak al plaatsvinden tijdens de inbedrijfstelling (op basis van metingen met fantomen), of vlak daarna op basis van een evaluatie van de stralingsbelasting bij klinisch onderzoek van patiënten. Later in de levenscyclus zal de routinematige kwaliteitscontrole aangeven of het systeem stabiel blijft voor wat betreft dosis en beeldkwaliteit. Bij geconstateerde afwijkingen zal een herstelactie worden ondernomen waarna bij het opnieuw in gebruik nemen van het toestel een kritische evaluatie plaats dient te vinden, eventueel inclusief toetsing aan de DRN's. Een voorbeeld van routinematige kwaliteitscontrole binnen de radiologie zijn de QC-light protocollen die met een zekere frequentie worden uitgevoerd [34].

\subsection{Inbedding van diagnostische referentieniveaus}

Bestaande inspanningen op het gebied van kwaliteitsborging en de toetsing aan DRN's, kunnen goed op elkaar aansluiten, bijvoorbeeld door DRN's in te passen binnen de levenscyclus van diagnostische röntgensystemen, zoals hierboven beschreven. Daarbij verdienen de volgende 6 punten aandacht:

1. Inventariseer alle potentiële gevaren. Eén van de potentiële gevaren bij radiologie is het risico dat verbonden is aan blootstelling met ioniserende straling. Toetsing aan de DRN's speelt een belangrijke rol bij het beheersen van dit risico. Een ander potentieel gevaar is ontoereikende beeldkwaliteit. Bij toetsing aan de DRN's dient in het oog te worden gehouden dat de beeldkwaliteit van het betreffende röntgenonderzoek voldoende moet zijn voor goede diagnostiek.

2. Stel de kritische beheerspunten vast, dat wil zeggen punten waar het risico kan worden voorkomen of beperkt. Kritische beheerspunten volgen ook uit het schema levenscyclus van apparatuur, bijvoorbeeld aanbesteding, inbedrijfstelling, kwaliteitscontrole. Binnen deze fases kan aandacht worden besteed aan de DRN's.

3. Geef de kritische grenzen aan. De kritische grenzen voor wat betreft stralingsbelasting voor de patiënt zijn de DRN's. Ook met betrekking tot beeldkwaliteit zijn uiteraard kritische grenzen aan de orde.

4. Bewaak de kritische grenzen. Het meten van klinische blootstellingen en het toetsen aan de diagnostische referentieniveaus vindt plaats ofwel voorafgaand aan de inbedrijfstelling (mammografie) ofwel vlak daarna bij de klinische ingebruikname (overige modaliteiten). Dit betreft inbedrijfstelling na de installatie maar ook na een omvangrijke reparatie van het apparaat (bijvoorbeeld reparatie aan de röntgenbuis of 
detector). Tevens dient te worden getoetst of de beeldkwaliteit binnen de vereiste kritische grenzen valt.

5. Leg correctieve acties vast. Wanneer niet wordt voldaan aan het DRN dient onderzocht te worden of bij een andere afregeling het dosisniveau wel voldoet aan het DRN en ook voldoende beeldkwaliteit geeft. Indien dit het geval is dient de nieuwe afregeling klinisch gebruikt te worden. Wanneer dit resultaat niet realiseerbaar blijkt zal buitenbedrijfstelling moeten worden overwogen.

6. Houd documentatie en registraties bij. Kortom, zorg voor een werkbaar archief voor wat betreft (periodieke) testen en onderhoud door de fabrikant. 


\section{Diagnostische referentieniveaus en streefwaarden}

\subsection{Mammografie}

\section{Methodiek}

Voor mammografie is een eenvoudig fantoom beschikbaar dat op brede schaal gebruikt wordt voor kwaliteitscontrole van de mammograaf en voor dosimetrie. Het fantoom bestaat uit stapelbare homogene platen polymethylmetacrylaat (PMMA) met een afmeting van ca. 18 $\mathrm{cm} \times 24 \mathrm{~cm}$ zodat het AEC-sensor gebied voldoende ruim bedekt is en verschillende dikten. De verzwakkende eigenschappen van PMMA zijn slechts bij benadering gelijk aan die van de gecomprimeerde borst. Daarom dient bij toetsing aan de DRN's bij iedere PMMA-dikte de overeenkomstige gecomprimeerde borstdikte in overweging te worden genomen. Op sommige mammografen wordt een indicatie gegeven van de geabsorbeerde dosis, echter de bepaling van deze waarde is niet gestandaardiseerd. Deze niveaus lijken daarom niet goed bruikbaar voor toetsing aan het referentieniveau. Mocht men niet over de benodigde instrumentatie beschikken (PMMA-platen en dosismeter) dan kunnen metingen bijvoorbeeld worden uitgevoerd in samenwerking met de fabrikant of leverancier van de mammograaf (bijvoorbeeld tijdens de acceptatietest en/of het periodieke onderhoud).

\section{Dosimetrische grootheid en eenheid}

Voor mammografie wordt de grootheid Gemiddelde Glandulaire Dosis (GGD), de gemiddelde geabsorbeerde dosis in het borstklierweefsel, met als eenheid mGy gebruikt.

\section{Referentieniveaus}

De GGD is gedefinieerd in het dosimetrische model van Dance [6-10]. In dit model wordt er onderscheid gemaakt tussen twee leeftijdsgroepen, namelijk 40-49 jaar en 50-64 jaar. De diagnostische referentieniveaus hebben betrekking op de leeftijdsgroep 50-64 jaar omdat mammografie overwegend voor deze leeftijdsgroep wordt toegepast. De referentieniveaus zijn ontleend aan de Europese Richtlijnen voor Kwaliteitsbewaking bij Screening op Borstkanker en Diagnostiek [35]. De GGD wordt mede bepaald door het röntgenspectrum waarmee de opname wordt gemaakt. De afregeling van de belichtingsautomaat is doorgaans voor dunne, gemiddelde en dikke borsten verschillend. Hierdoor is het definiëren van referentieniveaus voor alleen gemiddelde borsten niet voldoende. Er zijn daarom voor drie verschillende gesimuleerde borstdiktes, 3, 5 en 7 cm PMMA, referentieniveaus en streefwaarden gedefinieerd (Tabel I). 
Tabel la. Diagnostische referentieniveaus voor mammografie ${ }^{5}$, craniocaudale projectie. Gemiddelde Glandulaire Dosis (GGD, mGy) bepaald voor PMMA-platen van verschillende dikte en representatief voor de leeftijdsgroep 50-64 jaar.

\begin{tabular}{lcl}
\hline Fantoomdikte & $\begin{array}{c}\text { Equivalente gecomprimeerde } \\
\text { borstdikte }\end{array}$ & DRN $^{7}$ ) \\
\hline $3 \mathrm{~cm}$ PMMA & $3.2 \mathrm{~cm}$ & GGD 1.5 mGy \\
$5 \mathrm{~cm}$ PMMA & $6.0 \mathrm{~cm}$ & GGD $3.0 \mathrm{mGy}$ \\
$7 \mathrm{~cm}$ PMMA & $9.0 \mathrm{~cm}$ & GGD $6.5 \mathrm{mGy}$ \\
\hline
\end{tabular}

Tabel Ib. Streefwaarden voor mammografie, craniocaudale projectie.. Gemiddelde Glandulaire Dosis (GGD, mGy) bepaald voor PMMA-platen van verschillende dikte en representatief voor de leeftijdsgroep 50-64 jaar.

\begin{tabular}{lcl}
\hline Fantoomdikte & $\begin{array}{c}\text { Equivalente gecomprimeerde } \\
\text { borstdikte }\end{array}$ & Streefwaarde (DR) \\
\hline $3 \mathrm{~cm}$ PMMA & $3.2 \mathrm{~cm}$ & GGD 1.0 mGy \\
$5 \mathrm{~cm}$ PMMA & $6.0 \mathrm{~cm}$ & GGD 2.4 mGy \\
$7 \mathrm{~cm}$ PMMA & $9.0 \mathrm{~cm}$ & GGD 5.1 mGy \\
\hline
\end{tabular}

\section{Meetmethode dosiswaarden}

Bij toetsing aan de DRN's dient de intreedosis ter hoogte van het PMMA fantoom bepaald te worden. Dit kan worden gedaan d.m.v. een directe meting of kan worden afgeleid van de buisopbrengst. De intreedosis wordt bepaald bij gebruik van de (vol-) automatische belichtingsautomaat (zoals gebruikt in standaard klinische praktijk). Voor het bepalen van de gemiddelde glandulaire dosis moeten van het mammografiesysteem de halfwaarde-dikten (HVL) en indien de intreedosis niet gemeten wordt, de buisopbrengst bij alle mogelijk gebruikte spectra bekend zijn. Bij de meting wordt gebruik gemaakt van een eenvoudig fantoom van 3, 5 of $7 \mathrm{~cm}$ PMMA dat op de bucky wordt geplaatst. Over het algemeen is de hoogte van de compressieplaat bepalend voor de automatisch gekozen spectrale

\footnotetext{
${ }^{5}$ Uit "European guidelines for quality assurance in breast cancer screening and diagnosis" (Perry et al.) (Section 2a.2.5.1.) [35].

${ }^{6}$ Equivalente gecomprimeerde borstdikte die overeenkomt met de vermelde fantoomdikte (ter informatie)

${ }^{7}$ De dosis die nodig is voor opnamen met de 1e generatie enkelzijdig uitgelezen fosforplaten (CRsystemen) is relatief hoog om een goede beeldkwaliteit te kunnen halen. Het kan voorkomen dat deze systemen in de klinische praktijk worden toegepast bij een instelling (acquisitie techniek) die leidt tot een dosis hoger dan de vermelde diagnostische referentieniveaus.
} 
opnameparameters (anode/filtercombinatie en buisspanning). Om deze reden moet de hoogte van de compressieplaat gelijk zijn aan de equivalente gecomprimeerde borstdikte en niet aan de dikte van het PMMA. Indien het voor de belichtingsautomaat noodzakelijk is te comprimeren kan er extra materiaal aan het fantoom worden toegevoegd, om de compressieplaat op de gewenste hoogte te krijgen. Voorwaarde is uiteraard wel dat dit materiaal de röntgenbundel niet (of nauwelijks) verzwakt. Voor details m.b.t. de uitvoering van de meting en de berekening van de dosis in het borstklierweefsel wordt verwezen naar het protocol van het LRCB [31] en publicaties van Dance [6-10]. 


\subsection{CTPA-thorax en CT-abdomen}

\section{Methodiek}

Voor CT van de romp (thorax en abdomen) wordt de toetsing aan DRN's afgeleid van dosismetingen met het standaard CT-dosis romp fantoom. Deze dosimetrische techniek is goed ingebed in de klinische praktijk en wordt ook beschreven in internationale richtlijnen. Uit de dosismetingen kan de computer tomografie-dosisindex (CTDI) en het dosis-lengteproduct (DLP) worden afgeleid, deze dosiswaarden worden overigens in het algemeen voor elk CTonderzoek op de bedieningsconsole getoond, en (veelal als afbeelding) in het PACS opgeslagen. Wanneer de nauwkeurigheid van deze dosiswaarden voldoende is gebleken kunnen ze gebruikt worden voor toetsing aan DRN-waarden.

\section{Dosimetrische grootheid en eenheid}

De dosimetrische grootheden zijn de volume computer tomografie dosisindex (CTDI ${ }_{100, v o l}$, mGy, voor spiraal CT acquisities) of de gewogen computer tomografie dosisindex (CTDI ${ }_{100, w}$, mGy, voor axiale (step and shoot) CT acquisities) en het dosis-lengte product (DLP, $\mathrm{mGy} \cdot \mathrm{cm})$.

\section{Referentieniveaus}

Als gangbare representatieve CT-onderzoeken zijn respectievelijk gekozen: CTPA-thorax (klinische vraagstelling longembolie) en CT-abdomen (klinische vraagstelling acute buik). Het referentieniveau voor zowel CTPA, als het referentieniveau bij CT-abdomen heeft betrekking op de acquisitie van één enkel volume.

De referentieniveaus zijn onder andere ontleend aan het Nederlandse demonstratieproject patiëntendosimetrie [42] en een Europese veldstudie [12]. In het kader van deze studies werd in meer dan 40 ziekenhuizen dosimetrische data verzameld in de periode 2002-2003 voor een groot aantal verrichtingen. De streefwaarden zijn ontleend aan een publicatie van Van der Molen et al. uit 2007 [43] (Tabel II). 
Tabel Ila. Diagnostische referentieniveaus voor computer tomografie (één volume):

Computer tomografie dosisindex (voor een spiraal acquisitie CTDI ${ }_{100, v o l}$; bij een step and shoot acquisitie CTDI $\left.{ }_{100, w}, m G y\right)$ en dosis-lengte product (DLP, mGy.cm) bepaald voor een CT dosis romp fantoom ${ }^{8}$.

\section{CT-abdomen, klinische indicatie: acute buik}
CTDI $_{\text {vol100 }}$ of CTDI $_{100, w}$ :
15 mGy
DLP:
$700 \mathrm{mGy} \cdot \mathrm{cm}$

\section{CTPA-thorax, klinische indicatie: longembolie}
CTDI $_{\text {vol100 }}$ of CTDI ${ }_{100, w}$ :
10 mGy
DLP:
$350 \mathrm{mGy} \cdot \mathrm{cm}$

Tabel Ilb. Streefwaarden voor computer tomografie (één volume): Computer tomografie

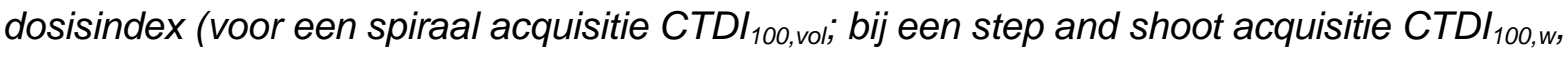
$m G y$ ) en dosis-lengte product (DLP, mGy.cm) bepaald voor een CT dosis romp fantoom.

\section{CT-abdomen, klinische indicatie: acute buik}
CTDI $_{\text {vol100 }}$ of CTDI $_{100, w}$ :
8 mGy
DLP:
$400 \mathrm{mGy} \cdot \mathrm{cm}$

\section{CTPA-thorax, klinische indicatie: longembolie}

$\begin{array}{lll}\text { CTDI }_{\text {vol100 }} \text { of } \mathrm{CTDI}_{100, \mathrm{w}}: & 6 & \mathrm{mGy} \\ \text { DLP: } & 200 & \mathrm{mGy} \cdot \mathrm{cm}\end{array}$

\section{Meetmethode dosiswaarden}

Bij de ingebruikname van nieuwe CT-scanners is het gebruikelijk de CTDI daadwerkelijk te meten. Deze meting dient om de buisopbrengst van de CT-scanner (uitgedrukt als CTDI) te toetsen aan de specificaties maar ook om de nauwkeurigheid van de indicatie van CTDI en DLP op de bedieningsconsole te controleren. Voor het uitvoeren van de metingen zijn speciaal hiervoor ontwikkelde fantomen nodig (CT-dosisfantoom) en de metingen worden in het algemeen uitgevoerd met een $100 \mathrm{~mm}$ lange CT-ionisatiekamer. Voor het meten van CTDI-niveaus en het berekenen van DLP wordt verwezen naar IEC 60601-2-44 [22] en [32].

Gebruikers van CT-scanners worden geacht de klinische CT-protocollen m.b.t. de bovenstaande vraagstellingen te toetsen aan de genoemde referentieniveaus. Dit kan

\footnotetext{
${ }^{8}$ Effectieve dosis (informatief): voor het berekenen van orgaandoses en de effectieve dosis zijn aanvullende berekeningen nodig. Voor een patiënt van gemiddeld postuur wordt geschat dat de effectieve dosis die verbonden is met de hierboven vermelde diagnostische referentieniveaus ongeveer $6 \mathrm{mSv}$ bedraagt voor CTPA van de thorax en ongeveer $10 \mathrm{mSv}$ voor CT buik/bekken.
} 
bijvoorbeeld aan de hand van de op de console getoonde (en door de gebruiker gevalideerde) CTDI- en DLP-niveaus. In dit geval dient de gebruiker zich ervan te verzekeren dat de nauwkeurigheid van de indicatie van de CTDI op de bedieningsconsole voldoende is. Bij toetsing aan de DRN wordt aanbevolen bij 20 patiënten dosiswaarden te registreren evenals het gewicht van de patiënt. Met de verkregen gegevens kan door middel van interpolatie de dosis worden afgeleid dat van toepassing is op de gemiddelde patiënt (gewicht $=77 \mathrm{~kg}$ ). Vervolgens kan deze waarde worden getoetst aan de referentiewaarde. 


\subsection{X-thorax en X-bekken}

\section{Methodiek}

Röntgentoestellen die worden gebruikt voor het maken van thoraxfoto's en opnamen van het bekken beschikken over het algemeen over een voorziening die het dosisoppervlakteproduct voor elke klinische opname meet en registreert. Toetsing van het diagnostische referentieniveau voor de röntgenopnamen wordt ontleend aan registraties van het dosis-oppervlakteproduct tijdens regulier klinisch onderzoek en heeft betrekking op een representatieve groep van patiënten. Op toestellen die niet zijn voorzien van deze functionaliteit kan (tijdelijk of permanent) een vlakke ionisatiekamer voor het meten van het dosis-oppervlakteproduct worden aangebracht.

\section{Dosimetrische grootheid en eenheid}

De dosimetrische grootheid is het dosis-oppervlakteproduct (DOP, in $\mu$ Gy.m ${ }^{2}$ ) [28;41].

\section{Referentieniveaus}

Het referentieniveau voor X-thorax heeft betrekking op de PA projectie (staand, zoals bijvoorbeeld bij de klinische vraagstelling infiltraten) en voor X-bekken op de AP projectie (AP bekken, liggend, zoals bij de klinische vraagstelling arthrose). Als bron is onder andere gebruik gemaakt van de resultaten uit het Nederlandse demonstratieproject patiëntendosimetrie [37;42]. Tijdens het demonstratieproject werd in de periode 2002-2003 uit 11 verschillende Nederlandse ziekenhuizen dosimetrische data verzameld voor een groot aantal verrichtingen. Hieruit konden de volgende diagnostische referentieniveaus en streefwaarden worden afgeleid (Tabel III): 
Tabel Illa. Diagnostische referentieniveaus voor röntgenopnamen bij volwassenen. Dosisoppervlakteproduct (DOP, $\mu \mathrm{Gy} . \mathrm{m}^{2}$ ) voor een gemiddelde patiënt met een gewicht van $77 \mathrm{~kg}^{9}$ 10

X-Thorax PA (wandbucky of thoraxstatief), klinische indicatie: infiltraten DOP $\quad 12 \mu G y \cdot m^{2}$

X-Bekken AP (tafelbucky) ${ }^{11}$, klinische indicatie: arthrose

DOP $\quad 300 \quad \mu G y \cdot m^{2}$

Tabel IIlb. Streefwaarden voor röntgenopnamen bij volwassenen, deze waarden hebben alleen betrekking op $D R^{12}$. Dosis-oppervlakteproduct (DOP, $\left.\mu G y . m^{2}\right)$ voor een gemiddelde patiënt met een gewicht van $77 \mathrm{~kg}$.

\section{X-Thorax PA (wandbucky of thoraxstatief), klinische indicatie: infiltraten}

DOP $6 \mu$ Ha.m ${ }^{2}$

\section{X-Bekken AP (tafelbucky), klinische indicatie: artrose}

DOP $150 \mu$ Gy.m ${ }^{2}$

\section{Meetmethode dosiswaarden}

Het dosis-oppervlakteproduct is over het algemeen eenvoudig op de bedieningsconsole af te lezen. Gebruikers dienen zich ervan te overtuigen dat de uitlezing van de dosisoppervlaktemeter voldoende nauwkeurig is, bijvoorbeeld door middel van kalibratie. Bij toetsing aan de DRN wordt aanbevolen bij 20 patiënten het DOP te registreren evenals het gewicht van de patiënt. Met de verkregen gegevens kan door middel van interpolatie het DOP worden afgeleid dat van toepassing is op de gemiddelde patiënt (gewicht $=77 \mathrm{~kg}$ ). Vervolgens kan deze waarde worden getoetst aan de referentiewaarde.

\footnotetext{
${ }^{9}$ De dosis die nodig is voor opnamen met fosforplaten (CR-systemen) en Film is veelal hoger dan bij DR-systemen om een goede beeldkwaliteit te kunnen halen.

${ }^{10}$ Effectieve dosis (informatief): Voor het berekenen van orgaandoses en de effectieve dosis zijn aanvullende berekeningen nodig. Voor een patiënt van gemiddeld postuur wordt geschat dat de effectieve dosis die verbonden is met de hierboven vermeldde diagnostische referentieniveaus ongeveer $0.03 \mathrm{mSv}$ bedraagt voor de PA thoraxopname en $0.6 \mathrm{mSv}$ voor het AP buikoverzicht.

${ }^{11}$ In sommige ziekenhuizen wordt een X-Bekken AP staand verricht. In dit geval kan men eveneens toetsen aan het genoemde DRN. Hetzelfde geldt voor de streefwaarde.

${ }^{12} \mathrm{Bij}$ DR systemen is, vanwege de relatief gevoelige detector, vaak een dosisniveau haalbaar dat aanzienlijk lager ligt dan het DRN, en waarbij tevens een goede beeldkwaliteit wordt verkregen.
} 
4.4. Kinderradiologie: röntgenopnamen (X-thorax, $X$-abdomen; leeftijd 0 (neonaat), 1 en 5 jaar)

\section{Methodiek}

Toestellen voor het maken van röntgenopnamen beschikken in het algemeen over een voorziening die het dosis-oppervlakte product meet en registreert dan wel deze berekent. Toetsing van het diagnostische referentieniveau voor de röntgenopnamen wordt ontleend aan registraties van het dosis-oppervlakte product-registraties tijdens regulier klinisch onderzoek en heeft betrekking op een representatieve groep van klinische patiënten. In de literatuur worden voor diagnostische referentieniveaus voor röntgenopnamen bij kinderen niet altijd eenduidige leeftijdsgroepen gehanteerd en soms worden naast leeftijdsgroep ook gewicht en/of lengte meegenomen. Omwille van de praktische toepasbaarheid is in dit protocol uitgegaan van leeftijdscategorieën. Aanvullend wordt in de tabellen ook het gemiddelde/standaard gewicht vermeld per leeftijdscategorie. Verder is bekend dat een substantieel aantal thoraxfoto's wordt gemaakt bij zeer jonge kinderen [44]. Voor kinderen vanaf bij benadering 10 jaar wordt voor thoraxfoto's de techniek voor volwassenen gebruikt. Bovenstaande overwegingen hebben geleid tot 3 leeftijdscategorieën: 0,1 en 5 jaar. Er worden dus geen leeftijdsintervallen gehanteerd maar discrete leeftijden. Dit geldt voor alle verrichtingen die hierna staan beschreven. Een en ander sluit aan bij de publicatie van Hart [18].

\section{Dosimetrische grootheid en eenheid}

De dosimetrische grootheid is het dosis-oppervlakte product (DOP, $\left.\mu \mathrm{Gy} \cdot \mathrm{m}^{2}\right)[28 ; 41]$.

\section{Referentieniveaus}

Tabel IV toont diagnostische referentieniveaus voor röntgenopnamen in de kinderradiologie, het betreft X-thorax en X-abdomen. DRN's zijn gebaseerd op DRN's in het Verenigd Koninkrijk (22), de streefwaarden zijn gebaseerd op een veldstudie van Geleijns in 9 Nederlandse ziekenhuizen uit 1998 [14]. Voor de gemiddelde waarden uit deze laatste studie werd verondersteld dat deze als haalbaar kunnen worden beschouwd, recente gegevens uit het LUMC voor digitale (DR) systemen ondersteunen dit [44]. 
Tabel IVa: Diagnostische referentieniveaus voor kinderradiologie: röntgenopnamen $X$-thorax, $X$ abdomen. Dosis-oppervlakte product (DOP, $\mu G y \cdot m^{2}$ ). DRN's zijn gebaseerd op DRN's in het Verenigd Koninkrijk [18].

\begin{tabular}{cccl}
\hline Leeftijd (jaar) & Gewicht $(\mathrm{kg})$ & Grid & CR, DR en Film ${ }^{13}$ \\
\hline X-Thorax AP/PA & & & \\
0 & 4 & Nee & DOP $1.5 \mu \mathrm{Gy} \cdot \mathrm{m}^{2}$ \\
1 & 11 & Nee & DOP $2.0 \mu \mathrm{Gy} \cdot \mathrm{m}^{2}$ \\
5 & 21 & Nee & DOP $5.0 \mu \mathrm{Gy} \cdot \mathrm{m}^{2}$ \\
\hline X-Abdomen AP & 4 & Nee & DOP $1.5 \mu \mathrm{Gy} \cdot \mathrm{m}^{2}$ \\
0 & 11 & Nee & DOP $10.0 \mu \mathrm{Gy} \cdot \mathrm{m}^{2}$ \\
1 & 21 & Ja & DOP $25.0 \mu \mathrm{Gy} \cdot \mathrm{m}^{2}$
\end{tabular}

Het dosis-oppervlakte product heeft betrekking op een veldgrootte van respectievelijk $15 \times 15 \mathrm{~cm}^{2} ; 18 \times 18 \mathrm{~cm}^{2}$, en $25 \times 25 \mathrm{~cm}^{2}$ voor 0 , 1 en 5 jaar (veldgrootte gemeten op de beelddrager). "Grid" geeft aan of er al dan niet een strooistralenrooster werd toegepast in relatie tot de gevonden dosiswaarde (het betreft geen advies m.b.t. het gebruik).

Tabel IVb: Streefwaarden voor kinderradiologie: röntgenopnamen $X$-thorax, $X$-abdomen. Dosis-oppervlakte product (DOP, Gy. $\mathrm{cm}^{2}$ ), deze waarden hebben alleen betrekking op DR. Streefwaarden zijn gebaseerd op de veldstudie van Geleijns [14].

\begin{tabular}{|c|c|c|c|c|}
\hline Leeftijd (jaar) & Gewicht (kg) & Grid & DR & \\
\hline \multicolumn{5}{|l|}{ X-Thorax AP/PA } \\
\hline 0 & 4 & Nee & DOP & $0.75 \mu \mathrm{Gy} \cdot \mathrm{m}^{2}$ \\
\hline 1 & 11 & Nee & DOP & $1.0 \mu \mathrm{Gy} \cdot \mathrm{m}^{2}$ \\
\hline 5 & 21 & Nee & DOP & $2.5 \mu \mathrm{Gy} \cdot \mathrm{m}^{2}$ \\
\hline \multicolumn{5}{|l|}{ X-Abdomen AP } \\
\hline 0 & 4 & Nee & DOP & $0.75 \mu \mathrm{Gy} \cdot \mathrm{m}^{2}$ \\
\hline 1 & 11 & Nee & DOP & $5.0 \mu \mathrm{Gy} \cdot \mathrm{m}^{2}$ \\
\hline 5 & 21 & $\mathrm{Ja}$ & DOP & $12.5 \mu G y \cdot m^{2}$ \\
\hline
\end{tabular}

Het dosis-oppervlakte product heeft betrekking op een veldgrootte van respectievelijk $15 \times 15 \mathrm{~cm}^{2} ; 18 \times 18 \mathrm{~cm}^{2}$, en $25 \times 25 \mathrm{~cm}^{2}$ voor 0 , 1 en 5 jaar (veldgrootte gemeten op de

\footnotetext{
${ }^{13}$ De dosis die nodig is voor opnamen met CR-systemen en röntgenfilm is veelal hoger dan bij DRsystemen.
} 
beelddrager). "Grid" geeft aan of er al dan niet een strooistralenrooster werd toegepast in relatie tot de gevonden dosiswaarde (het betreft geen advies m.b.t. het gebruik).

\section{Meetmethode dosiswaarden}

Het dosis-oppervlakte product is over het algemeen eenvoudig op de bedieningsconsole af te lezen. Gebruikers dienen zich ervan te overtuigen dat de uitlezing van het dosisoppervlakte product voldoende nauwkeurig is, bijvoorbeeld door middel van kalibratie. Bij toetsing aan de DRN wordt aanbevolen bij 20 patiënten per leeftijdscategorie het DOP te registreren. Met de verkregen gegevens kan het DOP worden afgeleid dat van toepassing is op de gemiddelde patiënt per leeftijdscategorie, bijvoorbeeld door het bepalen van de mediaan of het gemiddelde. Vervolgens kan deze waarde worden getoetst aan de referentiewaarde. 
4.5 Kinderradiologie: CT-hoofd; trauma (leeftijd 0 (neonaat), 1, 5 en 10 jaar)

\section{Methodiek}

Voor CT van het hoofd wordt de toetsing aan DRN's afgeleid van dosismetingen met het standaard CT-dosis hoofd fantoom. Deze dosimetrische techniek is goed ingebed in de klinische praktijk en hij wordt ook beschreven in internationale richtlijnen. Uit de dosismetingen kan de computer tomografie dosisindex (CTDI) en het dosis-lengte product (DLP) worden afgeleid, deze dosiswaarden worden overigens in het algemeen voor elk CTonderzoek op de bedieningsconsole getoond en (veelal als afbeelding) in het PACS opgeslagen. Wanneer de nauwkeurigheid van deze dosiswaarden voldoende is gebleken kunnen ze gebruikt worden voor toetsing aan DRN-waarden.

Voor de bovenstaande verrichtingen worden leeftijdsgroepen van 0, 1, 5 en 10 jaar te hanteren. Het criterium hiervoor was dat de verschillende leeftijdscategorieën een karakteristieke groep patiënten vertegenwoordigen.

\section{Dosimetrische grootheid en eenheid}

De dosimetrische grootheden zijn de volume computer tomografie dosisindex (CTDI ${ }_{100, v o l}$, mGy, voor spiraal CT acquisities) of de gewogen computer tomografie dosisindex (CTDI ${ }_{100, w}$, mGy, voor axiale (step and shoot) CT acquisities) en het dosis-lengte product (DLP, $\mathrm{mGy} \cdot \mathrm{cm})$.

\section{Referentieniveaus}

Tabel $\mathrm{V}$ toont diagnostische referentieniveaus en streefwaarden voor een toepasssing van CT in de kinderradiologie, het betreft CT-hoofd; trauma. Een Zwitserse studie heeft aan de basis gelegen van de hier vermelde DRN's [45]. De waarden uit deze veldstudie zijn geïnterpoleerd met betrekking tot de hier gehanteerde leeftijdscategorieën. Het DLP is afgeleid van een gangbare scan range voor de verschillende leeftijdsgroepen. De streefwaarden zijn gebaseerd op een Nederlands document van Nievelstein en van der Molen dat geoptimaliseerde protocollen beschrijt [33] en op persoonlijke communicatie met de auteurs. Het uitgangspunt bij alle waarden is een 16-slice scanner geweest. 
Tabel Va: Diagnostische referentieniveaus kinderradiologie: CT-hoofd; trauma. Computer tomografie dosisindex (voor een spiraal acquisitie CTDI ${ }_{100, \text { vol; }}$ bij een step and shoot acquisitie $\left.\left.C T D I_{100, w}\right), m G y\right)$ en dosis-lengte product (DLP, mGy.cm) bepaald voor een CT dosis hoofdfantoom.

\begin{tabular}{cclc}
\hline Leeftijd (jaar) & Gewicht $(\mathrm{kg})$ & \multicolumn{2}{c}{ DRN, trauma (hersenen) [45] } \\
\hline 0 & 4 & $C T D I_{100, \mathrm{vol} / \mathrm{w}} 20 \mathrm{mGy}$ & $D L P 240 \mathrm{mGy} \cdot \mathrm{cm}$ \\
1 & 11 & $C T D I_{100, \mathrm{vol} / \mathrm{w}} 25 \mathrm{mGy}$ & $D L P 300 \mathrm{mGy} \cdot \mathrm{cm}$ \\
5 & 21 & $C T D I_{100, \mathrm{vol} / \mathrm{w}} 35 \mathrm{mGy}$ & $D L P 420 \mathrm{mGy} \cdot \mathrm{cm}$ \\
10 & 36 & $C T D I_{100, \mathrm{vol} / \mathrm{w}} 50 \mathrm{mGy}$ & $D L P 600 \mathrm{mGy} \cdot \mathrm{cm}$
\end{tabular}

Het dosis-lengte product heeft betrekking op een scantraject van $12 \mathrm{~cm}$.

Tabel Vb: Streefwaarde kinderradiologie: CT-hoofd; trauma. Computer tomografie dosisindex (voor een spiraal acquisitie CTDI ${ }_{100, v o l}$; bij een step and shoot acquisitie CTDI $\left.\left.{ }_{100, w}\right), m G y\right)$ en dosis-lengte product (DLP, mGy.cm) bepaald voor een CT dosis hoofdfantoom.

\begin{tabular}{cccc}
\hline Leeftijd (jaar) & Gewicht $(\mathrm{kg})$ & \multicolumn{2}{c}{ Streefwaarde, (trauma) } \\
0 & 4 & $C T D I_{100, \mathrm{vol} / \mathrm{w}} 15 \mathrm{mGy}$ & (hersenen) $[45]$ \\
1 & 11 & $\mathrm{CTDI}_{100, \mathrm{vol} / \mathrm{w}} 20 \mathrm{mGy}$ & $D L P 240 \mathrm{mG} \cdot \mathrm{cm}$ \\
5 & 21 & $C T D I_{100, \mathrm{vo} / \mathrm{w}} 25 \mathrm{mGy}$ & $D L P 300 \mathrm{mGy} \cdot \mathrm{cm}$ \\
10 & 36 & $C T D I_{100, \mathrm{vol} / \mathrm{w}} 35 \mathrm{mGy}$ & $D L P 420 \mathrm{mGy} \cdot \mathrm{cm}$
\end{tabular}

Het dosis-lengte product heeft betrekking op een scantraject van $12 \mathrm{~cm}$.

\section{Meetmethode dosiswaarden}

Bij de ingebruikname van nieuwe CT-scanners is het gebruikelijk de CTDI daadwerkelijk te meten. Deze gemeten niveaus dienen om de buisopbrengst van de CT-scanner te toetsen aan de specificaties maar ook om de nauwkeurigheid van de indicatie van CTDI en DLP op de bedieningsconsole te controleren. Voor het uitvoeren van de metingen wordt een CT dosis fantoom gebruikt. De metingen worden in het algemeen uitgevoerd met een $100 \mathrm{~mm}$ lange CT-ionisatiekamer [21].

Gebruikers van CT-scanners worden geacht de klinische CT-protocollen m.b.t. de bovenstaande vraagstellingen te toetsen aan de genoemde referentieniveaus. Dit kan bijvoorbeeld aan de hand van de op de console getoonde CTDI- en DLP-niveaus. In dit geval

\footnotetext{
${ }^{14}$ Persoonlijke communicatie met R.A.J. Nievelstein
} 
dient de gebruiker zich ervan te verzekeren dat de nauwkeurigheid van de indicatie van de CTDI op de bedieningsconsole voldoende is.

Bij toetsing aan de DRN wordt aanbevolen per leeftijdscategorie bij 20 patiënten dosiswaarden te registreren evenals het gewicht van de patiënt. Met de verkregen gegevens kan door middel van interpolatie de dosis worden afgeleid dat van toepassing is op de gemiddelde patiënt (gewicht $=77 \mathrm{~kg}$ ). Vervolgens kan deze waarde worden getoetst aan de referentiewaarde. 
4.6 Kinderradiologie: Mictie Cysto-Urethrogram (MCUG; leeftijd 0 (neonaat), 1 en 5 jaar)

\section{Methodiek}

Doorlichtstatieven die worden gebruikt bij MCUG beschikken over het algemeen over een voorziening die het dosis-oppervlakte product meet en registreert. Toetsing van het diagnostische referentieniveau voor de röntgenopnamen wordt ontleend aan registraties van het dosis-oppervlakte product die plaatsvinden tijdens regulier klinisch onderzoek en heeft betrekking op een representatieve groep van klinische patiënten. Besloten is om voor de bovenstaande verrichting leeftijdsgroepen van 0,1 en 5 jaar te hanteren. Het criterium hiervoor was dat de verschillende leeftijdscategorieën een relevante groep patiënten vertegenwoordigen [44].

\section{Dosimetrische grootheid en eenheid}

De dosimetrische grootheid is het dosis-oppervlakte product (DOP, $\mu \mathrm{Gy} \cdot \mathrm{m}^{2}$;) [28;41].

\section{Referentieniveaus}

Tabel VI toont diagnostische referentieniveaus en streefwaarden voor Kinderradiologie: Mictie Cysto-Urethrogram (MCUG). De DRN's zijn overgenomen uit de publicatie van Hart, welke diagnostische referentieniveaus geeft voor het Verenigd Koninkrijk [17]. De streefwaarden zijn gebaseerd op de Nederlandse studie van Schultz [39]. Deze waarden worden ondersteund met gegevens uit diverse Nederlandse ziekenhuizen [44].

Tabel Vla: Diagnostische referentieniveaus voor kinderradiologie: Mictie CystoUrethrogram (MCUG ). Dosis-oppervlakte product (DOP, $\left.\mu G y \cdot m^{2}\right)$.

\begin{tabular}{lcc}
\hline Leeftijd (jaar) & Gewicht $(\mathrm{kg})$ & DRN $[17]$ \\
\hline 0 & 4 & DOP $30 \mu \mathrm{Gy} \cdot \mathrm{m}^{2}$ \\
1 & 11 & DOP $70 \mu \mathrm{Gy} \cdot \mathrm{m}^{2}$ \\
5 & 21 & DOP $80 \mu \mathrm{Gy} \cdot \mathrm{m}^{2}$ \\
\hline
\end{tabular}

Tabel VIb: Streefwaarden [39] voor kinderradiologie: Mictie Cysto-Urethrogram (MCUG). Dosis-oppervlakte product (DOP, $\left.\mu G y \cdot m^{2}\right)$.

\begin{tabular}{lcc}
\hline Leeftijd (jaar) & Gewicht $(\mathrm{kg})$ & Haalbare waarde [17] \\
\hline 0 & 4 & DOP $10 \mu \mathrm{Gy} \cdot \mathrm{m}^{2}$ \\
1 & 11 & DOP $20 \mu \mathrm{Gy} \cdot \mathrm{m}^{2}$ \\
5 & 21 & DOP $60 \mu \mathrm{Gy} \cdot \mathrm{m}^{2}$ \\
\hline
\end{tabular}




\section{Meetmethode dosiswaarden}

Het dosis-oppervlakte product is over het algemeen eenvoudig op de bedieningsconsole af te lezen. Gebruikers dienen zich ervan te overtuigen dat de uitlezing van de dosisoppervlaktemeter voldoende nauwkeurig is, bijvoorbeeld door middel van kalibratie.

Bij toetsing aan het DRN wordt aanbevolen bij 20 patiënten per leeftijdscategorie het DOP te registreren. Met de verkregen gegevens kan door bepaling van het gemiddelde of de mediaan het DOP worden afgeleid dat van toepassing is op de gemiddelde patiënt per leeftijdscategorie. Vervolgens kan deze waarde worden getoetst aan de referentiewaarde. 


\subsection{CT coronaire angiografie}

\section{Methodiek}

Voor CT van de thorax wordt de toetsing aan DRN's afgeleid van dosismetingen met het standaard CT-dosis romp fantoom. Deze dosimetrische techniek is goed ingebed in de klinische praktijk en hij wordt ook beschreven in internationale richtlijnen. Uit de dosismetingen kan de computer tomografie dosisindex (CTDI) en het dosis-lengte product (DLP) worden afgeleid, deze dosiswaarden worden overigens in het algemeen voor elk CTonderzoek op de bedieningsconsole getoond. Wanneer de nauwkeurigheid van deze getoonde waarden voldoende is gebleken (zie opmerkingen bij "Meetmethode dosiswaarden), kunnen ze gebruikt worden voor toetsing aan DRN-waarden.

\section{Dosimetrische grootheid en eenheid}

De dosimetrische grootheden zijn de volume computer tomografie dosisindex (CTDI ${ }_{100, v o l}$, mGy, voor spiraal CT acquisities) of de gewogen computer tomografie dosisindex $\left(C T D I_{100, w}\right.$, mGy, voor axiale (step and shoot) CT acquisities) en het dosis-lengte product (DLP, $\mathrm{mGy} \cdot \mathrm{cm})$.

\section{Referentieniveaus}

Tabel VIla toont diagnostische referentieniveaus voor diagnostische CT coronaire angiografie. De computer tomografie dosisindex (CTDI ${ }_{100, \text { vol }}$ of $\left.C T D I_{100, w}, \mathrm{mGy}\right)$ en het dosislengte product (DLP, mGy.cm) zijn bepaald voor een CT dosis rompfantoom. De waarden hebben betrekking op acquisitie met een 64-detector row CT scanner, en een retrospectieve ECG gated reconstructie zonder modulatie van de buisstroom. Deze waarden zijn ontleend aan een publicatie van Geleijns [15]. Pre-scans (voor het volgen van de contrast-bolus) zijn hierin niet meegenomen. Met behulp van nieuwe acquisitie- en reconstructie-technieken is een aanzienlijke dosisbesparing mogelijk. Tabel VIlb toont streefwaarden voor diagnostische CT coronaire angiografie die kunnen worden bereikt bij gebruik van dosisbesparende technieken. 
Tabel VIla. Diagnostische referentieniveau voor diagnostische CT coronaire angiografie. Computer tomografie dosisindex (voor een spiraal acquisitie CTDI ${ }_{100, v o l}$; bij een step and shoot acquisitie CTDI 100,w), mGy) en dosis-lengte product (DLP, mGy.cm) bepaald voor een CT dosis romp fantoom [15]. Interpolatie naar een gemiddelde patiënt met een gewicht van $77 \mathrm{~kg}$.

Spiraal CT met een retrospectieve ECG gated reconstructie zonder modulatie van de buisstroom

CTDI $_{100, v o l}$ of CTDI $100, w: 80 \mathrm{mGy} / \mathrm{DLP}: 1000 \mathrm{mGy} \cdot \mathrm{cm}$

Tabel VIlb: Streefwaarden voor diagnostische CT coronaire angiografie bij gebruik van dosisbesparende technieken. Computer tomografie dosisindex (voor een spiraal acquisitie CTDI ${ }_{100, v o l}$; bij een step and shoot acquisitie CTDI $\left.\left.{ }_{100, w}\right), m G y\right)$ en dosis-lengte product (DLP, mGy.cm) bepaald voor een CT dosis romp fantoom [15]. De waarden hebben betrekking op een gemiddelde patiënt met een gewicht van $77 \mathrm{~kg}$. Interpolatie naar een gemiddelde patiënt met een gewicht van $77 \mathrm{~kg}$.

Retrospective ECG gated reconstruction, helical acquisition

$\mathrm{CTDI}_{100, \mathrm{vol}}$ of CTDI $100, \mathrm{w}: 60 \mathrm{mGy} / \mathrm{DLP} 700 \mathrm{mGy.cm}$

Spiraal CT met een retrospectieve ECG gated reconstructie en ECG triggered modulatie van de buisstroom

(bij lage hartritmes $(<70)$

CTDI $_{100, \text { vol }}$ of CTDI ${ }_{100, w}: 50$ mGy / DLP 600 mGy.cm

\section{Step and shoot of spiral CT met een prospectieve ECG triggered acquisitie}

CTDI $_{100, \text { vol }}$ of CTDI $100, w: 25$ mGy / DLP 300 mGy.cm

\section{Meetmethode dosiswaarden}

Bij de ingebruikname van nieuwe CT-scanners is het gebruikelijk de CTDI daadwerkelijk te meten. Deze gemeten niveaus dienen om de buisopbrengst van de CT-scanner te toetsen aan de specificaties maar ook om de nauwkeurigheid van de indicatie van CTDI en DLP op de bedieningsconsole te controleren. Voor het uitvoeren van de metingen is een speciaal hiervoor ontwikkeld fantoom nodig (CT-dosis romp fantoom) en de metingen worden in het algemeen uitgevoerd met een $100 \mathrm{~mm}$ lange CT-ionisatiekamer [21].

Gebruikers van CT-scanners worden geacht de klinische CT-protocollen m.b.t. de bovenstaande vraagstellingen te toetsen aan de genoemde referentieniveaus. Dit kan 
bijvoorbeeld aan de hand van de op de console getoonde (en door de gebruiker gevalideerde) CTDI- en DLP-niveaus. In dit geval dient de gebruiker zich ervan te verzekeren dat de nauwkeurigheid van de indicatie van de CTDI op de bedieningsconsole voldoende is.

Bij toetsing aan de DRN wordt aanbevolen bij 20 patiënten dosiswaarden te registreren evenals het gewicht van de patiënt. Met de verkregen gegevens kan door middel van interpolatie de dosis worden afgeleid dat van toepassing is op de gemiddelde patiënt (gewicht $=77 \mathrm{~kg}$ ). Vervolgens kan deze waarde worden getoetst aan de referentiewaarde. 
4.8 Conventionele coronaire angiografie: diagnostisch

\section{Methodiek}

Doorlichtstatieven die worden gebruikt bij coronaire angiografie beschikken over het algemeen over een voorziening die het dosis-oppervlakte product meet en registreert. Toetsing van het diagnostische referentieniveau voor de hartcatheterisatie wordt ontleend aan registraties van het dosis-oppervlakte product die plaatsvinden tijdens regulier klinisch onderzoek en heeft betrekking op een representatieve groep van klinische patiënten.

\section{Dosimetrische grootheid en eenheid}

De vlakke ionisatiekamer registreert het dosis-oppervlakte product (DOP, $\mu \mathrm{Gy} \cdot \mathrm{m}^{2}$ ) door middel van een (veelal ingebouwde) dosismeter [28;41].

\section{Referentieniveaus}

Tabel VIIla toont diagnostische referentieniveaus voor diagnostische coronaire angiografie. Het dosis-oppervlakte product (DOP, $\mu \mathrm{Gy} \cdot \mathrm{m}^{2}$ ) heeft betrekking op een gemiddelde patiënt waarbij interpolatie heeft plaatsgevonden naar een gemiddelde patiënt met een gewicht van 77 kg. De DRN's in Zweden en Zwitserland zijn de basis voor het Nederlandse DRN [2;19]. Deze waarden zijn getoetst aan klinische praktijken in Nederland. De aanzienlijk lagere streefwaarde (Tabel VIIlb) is gebaseerd op de publicatie van Hart die DRN's publiceerde voor het Verenigd Koninkrijk [17].

Tabel VIIla: Diagnostische referentieniveaus voor conventionele diagnostische coronaire angiografie. Dosis-oppervlakte product (DOP, $\left.\mu G y \cdot m^{2}\right)$ gemeten bij 20 patiënten; interpolatie naar een gemiddelde patiënt met een gewicht van $77 \mathrm{~kg}$ [2;19].

DOP $8000 \mu \mathrm{Gy} \cdot \mathrm{m}^{2}$

Tabel VIIlb: Streefwaarde voor conventionele diagnostische coronaire angiografie Dosis-oppervlakte product (DOP, $\mu \mathrm{Gy} \cdot \mathrm{m}^{2}$ ) gemeten bij 20 patiënten; interpolatie naar een gemiddelde patiënt met een gewicht van $77 \mathrm{~kg}[17]$.

DOP $\quad 3000 \mu \mathrm{Gy} \cdot \mathrm{m}^{2}$

\section{Meetmethode dosiswaarden}

Het dosis-oppervlakte product is over het algemeen eenvoudig op de bedieningsconsole af te lezen. Gebruikers dienen zich ervan te overtuigen dat het dosis-oppervlakte product voldoende nauwkeurig is, bijvoorbeeld door middel van kalibratie. 
Bij toetsing aan de DRN wordt aanbevolen bij 20 patiënten het DOP te registreren (aanvullend kan het gewicht van de patiënt worden geregistreerd). Uit de verkregen DOP waarden kan de mediaan worden afgeleid. Vervolgens kan deze mediaan-waarde worden getoetst aan de referentiewaarde. De procedure wijkt af van die bij andere verrichtingen omdat bij deze specifieke verrichting de DOP-waarde matig tot slecht gecorreleerd is met het gewicht. 
4.9 Overzicht van alle DRN's en streefwaarden

Tabel la. Diagnostische referentieniveaus voor mammografie, craniocaudale projectie. Gemiddelde Glandulaire Dosis (GGD, mGy) bepaald voor PMMA-platen van verschillende dikte en representatief voor de leeftijdsgroep 50-64 jaar.

\begin{tabular}{lcl}
\hline Fantoomdikte & $\begin{array}{c}\text { Equivalente gecomprimeerde } \\
\text { borstdikte }\end{array}$ & DRN \\
\hline $3 \mathrm{~cm}$ PMMA & $3.2 \mathrm{~cm}$ & GGD $1.5 \mathrm{mGy}$ \\
$5 \mathrm{~cm}$ PMMA & $6.0 \mathrm{~cm}$ & GGD $3.0 \mathrm{mGy}$ \\
$7 \mathrm{~cm}$ PMMA & $9.0 \mathrm{~cm}$ & G GD $6.5 \mathrm{mGy}$
\end{tabular}

Tabel Ila. Diagnostische referentieniveaus voor computer tomografie: Computer tomografie dosisindex (voor een spiraal acquisitie CTDI ${ }_{100, v o l}$; bij een step and shoot acquisitie CTDI $\left.{ }_{100, w}, m G y\right)$ en dosis-lengte product (DLP, mGy.cm) bepaald voor een CT dosis romp fantoom.

\section{CT-buik/bekken, klinische indicatie: acute buik}

CTDI $_{\text {vol100 }}$ of CTDI $_{100, w}$ : $\quad 15$ mGy

DLP:

$700 \mathrm{mGy} \cdot \mathrm{cm}$

CT pulmonale angiografie-thorax, klinische indicatie: longembolie

CTDI $_{\text {vol100 }}$ of $\mathrm{CTDI}_{100, \mathrm{w}}$ : $\quad 10$ mGy

DLP: $\quad 350 \quad \mathrm{mGy} \cdot \mathrm{cm}$

Tabel IIla. Diagnostische referentieniveaus voor röntgenopnamen.bij volwassenen. Dosisoppervlakteproduct (DOP, $\left.\mu G y . m^{2}\right)$ voor een gemiddelde patiënt met een gewicht van 77 $\mathrm{kg}$.

X-Thorax PA (wandbucky of thoraxstatief), klinische indicatie: infiltraten DOP $\quad 12 \mu$ My.m $m^{2}$

\section{X-Bekken AP (tafelbucky) klinische indicatie: arthrose}

DOP $\quad 300 \quad \mu$ Gy.m2


Tabel IVa: Diagnostische referentieniveaus voor kinderradiologie: röntgenopnamen $X$ thorax, $X$-abdomen. Dosis-oppervlakte product (DOP, $\left.\mu G y \cdot m^{2}\right)$. DRN's zijn gebaseerd op DRN's in het Verenigd Koninkrijk [18].

\begin{tabular}{cccl}
\hline Leeftijd (jaar) & Gewicht $(\mathrm{kg})$ & Grid & CR, DR en Film ${ }^{15}$ \\
\hline X-Thorax AP/PA & & & \\
0 & 4 & Nee & DOP $1.5 \mu \mathrm{Gy} \cdot \mathrm{m}^{2}$ \\
5 & 11 & Nee & DOP $2.0 \mu \mathrm{Gy} \cdot \mathrm{m}^{2}$ \\
\hline X-Abdomen AP & 21 & Nee & DOP $5.0 \mu \mathrm{Gy} \cdot \mathrm{m}^{2}$ \\
0 & 4 & Nee & DOP $1.5 \mu \mathrm{Gy} \cdot \mathrm{m}^{2}$ \\
1 & 11 & Nee & DOP $10.0 \mu \mathrm{Gy} \cdot \mathrm{m}^{2}$ \\
5 & 21 & Ja & DOP $25.0 \mu \mathrm{Gy} \cdot \mathrm{m}^{2}$ \\
\hline
\end{tabular}

Het dosis-oppervlakte product heeft betrekking op een veldgrootte van respectievelijk $15 \times 15 \mathrm{~cm}^{2} ; 18 \times 18 \mathrm{~cm}^{2}$, en $25 \times 25 \mathrm{~cm}^{2}$ voor 0 , 1 en 5 jaar (veldgrootte gemeten op de beelddrager). "Grid" geeft aan of er al dan niet een strooistralenrooster wordt toegepast.

Tabel Va: Diagnostische referentieniveaus kinderradiologie: CT-hoofd; trauma. Computer

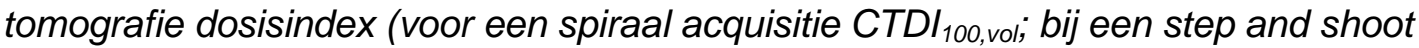
acquisitie $\left.\left.C T D I_{100, w}\right), m G y\right)$ en dosis-lengte product (DLP, mGy.cm) bepaald voor een CT dosis hoofdfantoom.

\begin{tabular}{cclc}
\hline Leeftijd (jaar) & Gewicht $(\mathrm{kg})$ & \multicolumn{2}{c}{ DRN, trauma (hersenen) [46] } \\
\hline 0 & 4 & $C T D I_{100, \mathrm{vol} / \mathrm{w}} 20 \mathrm{mGy}$ & $D L P 240 \mathrm{mGy} \cdot \mathrm{cm}$ \\
1 & 11 & $C T D I_{100, \mathrm{vol} / \mathrm{w}} 25 \mathrm{mGy}$ & $D L P 300 \mathrm{mGy} \cdot \mathrm{cm}$ \\
5 & 21 & $C T D I_{100, \mathrm{vo} / \mathrm{w}} 35 \mathrm{mGy}$ & $D L P 420 \mathrm{mGy} \cdot \mathrm{cm}$ \\
10 & 36 & $C T D I_{100, \mathrm{vol} / \mathrm{w}} 50 \mathrm{mGy}$ & $D L P 600 \mathrm{mGy} \cdot \mathrm{cm}$ \\
\hline
\end{tabular}

Het dosis-lengte product heeft betrekking op een scantraject van $12 \mathrm{~cm}$.

\footnotetext{
${ }^{15}$ De dosis die nodig is voor opnamen met CR-systemen en röntgenfilm is veelal hoger dan bij DRsystemen.
} 
Tabel Vla: Diagnostische referentieniveaus voor kinderradiologie: Mictie CystoUrethrogram (MCUG ). Dosis-oppervlakte product (DOP, $\mu G y \cdot m^{2}$ ).

\begin{tabular}{lcc}
\hline Leeftijd (jaar) & Gewicht $(\mathrm{kg})$ & DRN [17] \\
\hline 0 & 4 & DOP $30 \mu \mathrm{Gy} \cdot \mathrm{m}^{2}$ \\
1 & 11 & DOP $70 \mu \mathrm{Gy} \cdot \mathrm{m}^{2}$ \\
5 & 21 & DOP $80 \mu \mathrm{Gy} \cdot \mathrm{m}^{2}$ \\
\hline
\end{tabular}

Tabel VIla. Diagnostische referentieniveau voor CT coronaire angiografie. Computer tomografie dosisindex (voor een spiraal acquisitie CTDI ${ }_{100, v o l}$; bij een step and shoot acquisitie CTDI ${ }_{100, w}$ ), $m G y$ ) en dosis-lengte product (DLP, mGy.cm) bepaald voor een CT dosis romp hoofdfantoom [15]. Interpolatie naar een gemiddelde patiënt met een gewicht van $77 \mathrm{~kg}$.

Spiraal CT met een retrospectieve ECG gated reconstructie zonder modulatie van de
buisstroom
CTDI $_{100, \text { vol }}$ of $\mathrm{CTDl}_{100, \mathrm{w}}: 80 \mathrm{mGy} / \mathrm{DLP}: 1000 \mathrm{mGy} \cdot \mathrm{cm}$

Tabel VIIla: Diagnostische referentieniveaus voor conventionele diagnostische coronaire angiografie. Dosis-oppervlakte product (DOP, $\mu G y \cdot m^{2}$ ) gemeten bij 20 patiënten; interpolatie naar een gemiddelde patiënt met een gewicht van $77 \mathrm{~kg}$ [2;19].

DOP $8000 \mu \mathrm{Gy} \cdot \mathrm{m}^{2}$




\section{Referenties}

1. Aroua A, Besancon A, Buchillier-Decka I, Trueb P, Valley JF, Verdun FR, Zeller $W$. Adult reference levels in diagnostic and interventional radiology for temporary use in Switzerland. Radiation Protection Dosimetry 2004; 111:289-295.

2. Aroua A, Rickli H, Stauffer JC, Schnyder P, Trueb PR, Valley JF, Vock P, Verdun FR. How to set up and apply reference levels in fluoroscopy at a national level. European Radiology 2007; 17:1621-1633.

3. Bijwaard, $\mathrm{H}$ and Stoop, P. Kwaliteitsborging van radiodiagnostische apparatuur Overzicht van publicaties sinds 2004. RIVM rapport 300080001. 2007. Bilthoven, RIVM.

4. Bundesamt für Strahlenschutz. Bekanntmachung der diagnostischen Referenzwerte für radiologische und nuklearmedizinische Untersuchungen. 2003. Rapport van het Bundesamt für Strahlenschutz.

5. Centrum voor ouder en gezin. Groeigids 4-14 jaar. Een uitgave van het Ouder en Kind Centrum, Centrum voor Jeugd en Gezin, www.groeigids.nl, 2009.

6. Dance DR. Monte-Carlo Calculation of Conversion Factors for the Estimation of Mean Glandular Breast Dose. Physics in Medicine and Biology 1990; 35:12111219.

7. Dance DR, Klang AT, Sandborg M, Skinner CL, Smith IAC, Carlsson GA. Influence of anode/filter material and tube potential on contrast, signal-to-noise ratio and average absorbed dose in mammography: a Monte Carlo study. British Journal of Radiology 2000; 73:1056-1067.

8. Dance DR, Klang AT, Sandborg M, Skinner CL, Smith IAC, Carlsson GA. Influence of anode/filter material and tube potential on contrast, signal-to-noise ratio and average absorbed dose in mammography: a Monte Carlo study. British Journal of Radiology 2000; 73:1056-1067.

9. Dance DR, Skinner CL, Young KC, Beckett JR, Kotre CJ. Additional factors for the estimation of mean glandular breast dose using the UK mammography dosimetry protocol. Physics in Medicine and Biology 2000; 45:3225-3240.

10. Dance DR, Young KC, van Engen RE. Further factors for the estimation of mean glandular dose using the United Kingdom, European and IAEA breast dosimetry protocols. Physics in Medicine and Biology 2009; 54:4361-4372.

11. European Commission. Radiation protection 109, guidance on diagnostic reference levels (DRLs) for medical exposures. 1999. Report of the DirectorateGeneral Environment, Nuclear Safety and Civil Protection of the European Union. 
12. European Study Group on CT. Computed tomography: techniques, image quality and patient dose. Report of contract FIGM-CT2000-20078-CT-TIP. 2004. www.msct.eu.

13. Galanski, M., Hidajat, N., Maier, W., Nagel, H. D., and Schmidt, Th. Radiation exposure in computed tomography, fundamentals, Influencing parameters, dose assessment, optimisation, scanner data, terminology. Nagel, H. D. 4th revised and updated edition. 2002. Hamburg, CTB Publications.

14. Geleijns, J. Stralenbelasting bij kinderradiologie: een vergelijkend onderzoek in 9 Nederlandse ziekenhuizen. 1998.

15. Geleijns J, Joemai RM, Dewey M, Roos de A, Zankl M, Calzado Cantera A, Salvadó Artells M. A multicenter Coronary CT Angiography trial (CorE64): aspects of radiation exposure and risk assessment. American Journal of Roentgenology 2009; 196:1126-32.

16. Gezondheidsraad. Risico's van blootstelling aan ioniserende straling. publicatienr. 2007/03. 2007. Den Haag, Gezondheidsraad.

17. Hart D, Hillier MC, Wall BF. National reference doses for common radiographic, fluoroscopic and dental X-ray examinations in the UK. British Journal of Radiology 2009; 82:1-12.

18. Hart D, Wall BF, Shrimpton PC, Dance DR. The establishment of reference doses in paediatric radiology as a function of patient size. Radiation Protection Dosimetry 2000; 90:235-238.

19. Holm, L-E and Leitz, W. The Swedisch Radiation Protection Authority's regulations and general advice on diagnostic standard doses and reference levels within medical X-ray diagnostics. 2002.

20. ICRU. Patient Dosimetry for X Rays used in Medical Imaging (Report 74). 2005.

21. IEC. International Standard IEC 60601-2-44. 2002.

22. IEC. Medical electrical equipment -Part 2-44: Particular requirements for the safety of X-ray equipment for computed tomography. IEC 60601-2-44. 2002. IEC.

23. Institute of Physics and Engineering in Medicine. Recommended standards for the routine performance testing of diagnostic $x$-ray imaging systems. IPEM report 91. 2005. York, IPEM.

24. Institute of Physics and Engineering in Medicine DRL Working Party. Guidance and Use of Diagnostic Reference Levels for Medical X-Ray Examinations. IPEM Report 88 . 2004. York, IPEM. 
25. International Atomic Energy Agency (1996) BSS. International Basic Safety Standards, Protection against lonizing Radiation and for the Safety of Radiation Sources. Safety Series No. 115. 1996. International Atomic Energy Agency.

26. International Atomic Energy Agency (2007). Dosimetry in Diagnostic Radiology: an International Code of Practice. Technical Reports Series No. 457. 2007. International Atomic Energy Agency.

27. International Commission on Radiological Protection. Radiological Protection and Safety in Medicine. ICRP Publication 73. 1996. Oxford, Pergaman Press. Annals of the ICRP 26 (2).

28. International Electrotechnical Commission. IEC 60580 ed2.0 Medical electrical equipment - Dose area product meters . 2000.

29. Koningin Beatrix. Besluit van 16 juli 2001, houdende vaststelling van het besluit stralingsbescherming. Staatsblad 397. 2001. Den Haag, SDU Uitgevers.

30. Kotre CJ, Reay J, Chapple CL. The influence of patient size on patient doses in cardiology. Radiation Protection Dosimetry 2006; 117:222-224.

31. Landelijk Referentie Centrum voor Bevolkingsonderzoek op Borstkanker. Meetprotocol: Fysisch-technische testen van mammografie-apparatuur in de Nederlandse Borstkankerscreening. Versie: 2.2Januari 2010. 2010. Nijmegen, LRCB.

32. McNitt-Gray MF. AAPM/RSNA physics tutorial for residents: Topics in CT Radiation dose in CT1. Radiographics 2002; 22:1541-1553.

33. Nievelstein, R. A. J. and Molen van der A.J. Multislice CT op de kinderleeftijd. 111-2008.

34. NVKF. QC-light. http://www.nvkf.nl/read/qc_light. 2004.

35. Perry et al. European guidelines for quality Assurance in breast cancer screening and diagnosis, fourth edition. 2006. European Commission.

36. Reay J, Chapple CL, Kotre CJ. Is patient size important in dose determination and optimization in cardiology? Physics in Medicine and Biology 2003; 48:38433850 .

37. RIVM. Informatiesysteem Medische Stralingstoepassingen. www.rivm.nl/ims . 2008.

38. Saxebol G, Olerud HM, Hjardemaal O, Leitz W, Servomaa A, Walderhaug T. Nordic guidance levels for patient doses in diagnostic radiology. Radiation Protection Dosimetry 1998; 80:99-101.

39. Schultz FW, Geleijns J, Holscher HC, Weststrate J, Zonderland HM, Zoetelief J. Radiation burden to paediatric patients due to micturating cystourethrography 
examinations in a Dutch children's hospital. British Journal of Radiology 1999; 72:763-772.

40. Shrimpton, P. C., Hillier, M. C., Lewis, M. A., and Dunn, M. Doses from Computed Tomography (CT) Examinations in the UK - 2003 Review. NRPBW67. 2005. Chilton, NRPB.

41. Shrimpton PC, Wall BF. An Evaluation of the Diamentor Transmission IonizationChamber in Indicating Exposure Area Product (R-Cm2) During Diagnostic Radiological Examinations. Physics in Medicine and Biology 1982; 27:871-878.

42. Teeuwisse W, Geleijns J, Veldkamp W. An inter-hospital comparison of patient dose based on clinical indications. European Radiology 2007; 17:1795-1805.

43. van der Molen AJ, Veldkamp WJH, Geleijns J. 16-slice CT: achievable effective doses of common protocols in comparison with recent CT dose surveys. British Journal of Radiology 2007; 80:248-255.

44. Veldkamp, W. and Zweers, D. DRN werkgroep document; Dosisgegevens uit verschillende Nederlandse ziekenhuizen. 2009.

45. Verdun FR, Gutierrez D, Vader JP, Aroua A, Alamo-Maestre LT, Bochud F, Gudinchet F. CT radiation dose in children: a survey to establish age-based diagnostic reference levels in Switzerland. European Radiology 2008; 18:19801986.

46. Wall, B. F. Diagnostic reference levels in the x-ray department. Eur radiol Syllabus 14, 66-73. 2004.

47. Wall BF. Implementation of DRLs in the UK. Radiation Protection Dosimetry $2005 ; 114: 183-187$. 